Article

\title{
Capacity of the PERSIANN-CDR Product in Detecting Extreme Precipitation over Huai River Basin, China
}

\author{
Shanlei Sun ${ }^{1, * \mathbb{C}}$, Jiazhi Wang ${ }^{1}$, Wanrong Shi ${ }^{1}$, Rongfan Chai ${ }^{1}$ and Guojie Wang ${ }^{2} \mathbb{C}$ \\ 1 Collaborative Innovation Center on Forecast and Evaluation of Meteorological Disasters/Key Laboratory of \\ Meteorological Disaster, Ministry of Education/International Joint Research Laboratory on Climate and \\ Environment Change, Nanjing University of Information Science and Technology, Nanjing 210044, China; \\ 20191201122@nuist.edu.cn (J.W.); 20181201117@nuist.edu.cn (W.S.); rfchai@nuist.edu.cn (R.C.) \\ 2 School of Geographical Sciences, Nanjing University of Information Science and Technology, \\ Nanjing 210044, China; gwang@nuist.edu.cn \\ * Correspondence: sun.s@nuist.edu.cn; Tel.: +86-025-5869-5622
}

Citation: Sun, S.; Wang, J.; Shi, W.; Chai, R.; Wang, G. Capacity of the PERSIANN-CDR Product in Detecting Extreme Precipitation over Huai River Basin, China. Remote Sens. 2021, 13, 1747. https://doi.org/ $10.3390 /$ rs 13091747

Academic Editor: Joo-Heon Lee

Received: 23 March 2021

Accepted: 28 April 2021

Published: 30 April 2021

Publisher's Note: MDPI stays neutral with regard to jurisdictional claims in published maps and institutional affiliations.

Copyright: () 2021 by the authors. Licensee MDPI, Basel, Switzerland. This article is an open access article distributed under the terms and conditions of the Creative Commons Attribution (CC BY) license (https:// creativecommons.org/licenses/by/ $4.0 /)$.

\begin{abstract}
Assessing satellite-based precipitation product capacity for detecting precipitation and linear trends is fundamental for accurately knowing precipitation characteristics and changes, especially for regions with scarce and even no observations. In this study, we used daily gauge observations across the Huai River Basin (HRB) during 1983-2012 and four validation metrics to evaluate the Precipitation Estimation from Remotely Sensed Information Using Artificial Neural Networks-Climate Data Record (PERSIANN-CDR) capacity for detecting extreme precipitation and linear trends. The PERSIANN-CDR well captured climatologic characteristics of the precipitation amount- (PRCPTOT, R85p, R95p, and R99p), duration- (CDD and CWD), and frequency-based indices (R10mm, R20mm, and Rnnmm), followed by moderate performance for the intensity-based indices (Rx1day, R5xday, and SDII). Based on different validation metrics, the PERSIANN-CDR capacity to detect extreme precipitation varied spatially, and meanwhile the validation metric-based performance differed among these indices. Furthermore, evaluation of the PERSIANN-CDR linear trends indicated that this product had a much limited and even no capacity to represent extreme precipitation changes across the HRB. Briefly, this study provides a significant reference for PERSIANN-CDR developers to use to improve product accuracy from the perspective of extreme precipitation, and for potential users in the HRB.
\end{abstract}

Keywords: extreme precipitation index; PERSIANN-CDR; KGE; linear trend; Huai River Basin

\section{Introduction}

With successive and rapid warming during the past decades, increasing evidence suggests that climate extremes (e.g., extreme precipitation, heatwaves, and droughts) have changed across the world [1]. Of climate extremes, extreme precipitation is believed to be one major cause of the water-related disasters, e.g., floods and landslides [2-5]. These water-related disasters often result in enormous loss of life and destruction and have become a major obstacle to the sustainable development of society and the economy [6-8]. The Global Emergency Disaster Database stated that from 1970 to 2013 across the world, more than ten thousand water-related disasters happened, impacting more than 6.6 billion people, and leading to more than USD 2600 billion in damage, with the death of 3.5 million people [9]. In one word, the adverse impact induced by extreme precipitation on life and socio-economy are enormous, and therefore it is very necessary and critical to understand extreme precipitation (e.g., spatial patterns, changes, and underlying mechanisms) to reduce the related disasters and to develop reasonable prevention strategies.

Despite that, studying extreme precipitation still presents immense challenges because of difficulties in obtaining accurate, uninterrupted, and uniform precipitation data 
at the regional and global scale. So far, three pathways are employed to measure precipitation, i.e., direct observation with various gauges and retrievals from radar and satellite techniques. Gauge precipitation is believed to be the most accurate measurement [10]. However, due to inaccessibility and higher costs for installations and maintenance, there are issues to using gauge precipitation, i.e., limited spatial representativeness and coverage, time discontinuity, and short time span [11]. In view of this, gauge precipitation cannot fully satisfy the specific requirements of academic studies and practical applications, e.g., long-term ( $>30$ years), continuous (space and time) precipitation observations for climate studies. Radar-based precipitation retrievals have filled gaps in gauge precipitation to some extent, e.g., more extensive coverage. However, radar-based precipitation still has potential issues, e.g., the backwardness of radar technology in some countries and radar blockage due to topography [12-14]. In the past decades, very great advances have been made in technologies of satellites and sensors. Subsequently, various satellite-based precipitation products have been proposed based on radiance information received by satellite-carried sensors and different statistical and/or physics-based retrieval algorithms, such as Tropical Rainfall Measuring Mission (TRMM) Multi-Satellite Precipitation Analysis (GSFC; [15]); the National Oceanic and Atmospheric Administration (NOAA) Climate Prediction Center (CPC) morphing technique (CMORPH; [16]); the Global Satellite Mapping of Precipitation Microwave-IR Combined Product (GSMaP; [17]), the Precipitation Estimation from Remotely Sensed Information Using Artificial Neural Networks (PERSIANN; [18]); the Integrated Multisatellite Retrievals for Global Precipitation Measurement (IMERG; [19]); and the Climate Hazards Group InfraRed Precipitation with Station Data (CHIRPS; [20]). These satellite-based products provide an opportunity for academic studies and practical applications to fulfill various requirements of precipitation data.

Considering specific needs and goals, it is necessary to conduct quantitative evaluations of a given satellite-based precipitation product using dependable reference data, which can improve the confidence level of the related academic studies and ensure high efficiencies in practical applications. Studies have extensively assessed various satellitebased precipitation data over the world with a variety of statistical metrics [11,21-23]. For example, Shen et al. [21] suggested that CMORPH performed better than TRMMM and PERSIANN in capturing spatial and temporal variations in most of China, especially for reproducing summer precipitation characteristics. Tan et al. [22] compared multiple satellitebased precipitation estimates over Malaysia and found that TRMM showed higher coincidence with the observational precipitation. Results from Alijanian et al. [11] showed that Multi-Source Weighted-Ensemble Precipitation (MSWEP), PERSIANN-Climate Data Record (CDR), and TRMM could better identify rainfall and non-rainfall events in Iran, and PERSIANN-CDR had higher capacity than the other datasets in representing heavy rainfall. These studies provided references for theoretical understanding, and development of satellite-retrieved methodologies and their practical applications.

In China, more and more evidence indicates that extreme precipitation and related disasters have varied [24]. Taking the Huai River Basin (HRB) as an example, it frequently suffers from floods, with more than 350 floods during the past 50 decades and local and regional floods occurring nearly every two years [25]. Since the beginning of the 21st century, several severe extreme precipitation events (e.g., 2003, 2005, and 2007) and related floods happened in the HRB $[25,26]$. Incomplete statistics reported that more than 58 million people in the HRB were affected by the 2003 floods, with the flood-affected arable area exceeding $52,000 \mathrm{~km}^{2}, 390$ thousand houses collapsed, and direct economic losses of more than CNY 35 billion [27]. Yin et al. [28] projected that extreme precipitation with return periods of 20- and 50-years during 2001-2050 would considerably increase with exacerbating global warming, particularly in some places with increases of more than $30 \%$; this implies that the HRB has the potential to face a larger flood risk in future. Therefore, reasonably managing extreme precipitation-induced floods and taking efficient prevention measures are very important for regional and national food security and food production capacity. To this end, selecting a reliable, long-term, continuous precipita- 
tion measurement strategy with a relatively high spatio-temporal resolution is of much significance when attempting to mitigate the extreme precipitation-induced flood risk in the HRB; consequently, we chose the PERSIANN-CDR precipitation product here for evaluation with a high density of gauge records. Despite the fact that this product has been assessed over different regions of the world and even in China [23,29-32], issues still exist. For example, how good is the overall performance (e.g., Kling-Gupta Efficiency (KGE), which integrates impacts of bias, variability, and correlation coefficient on the overall performance [33]) of the PERSIANN-CDR in detecting extreme precipitation, and does this product reproduce linear trends of extreme precipitation? Particularly, the latter issue has been paid more and more attention in recent years (e.g., [34,35]) because the assessments regarding precipitation trends are the necessary foundation on which to accurately explore precipitation long term changes, especially for the regions with limited and even no observations. Therefore, this study aimed to: (1) comprehensively validate the PERSIANN-CDR performance in detecting different extreme precipitation indices (e.g., the precipitation amount-, duration-, and intensity-based indices) over the HRB, based on four validation metrics (i.e., three continuous validation metrics and one overall performance metric), and (2) detect the PERSIANN-CDR capacity to reproduce linear trends of various extreme precipitation indices. Results of this study will serve as a valuable reference for potential users in the HRB and for the PERSIANN-CDR developers to use to improve the algorithm for obtaining a more accurate extreme precipitation product.

\section{Data and Methodology}

\subsection{Study Region and Data}

The HRB is located in eastern China between $30-39^{\circ} \mathrm{N}$ and $111-123^{\circ} \mathrm{E}$ (Figure 1). It has a drainage area of approximately $33,000 \mathrm{~km}^{2}$, covering the northern parts of Jiangsu and Anhui, a small part of Hubei, and most of Shandong and Henan. The HRB has a vast plain, with many lakes and depressions, and is moderately mountainous (elevation generally from 1000 to $2000 \mathrm{~m}$ above sea level) near the western boundary, mid-eastern part, and Shandong peninsula. A typical semi-humid monsoon climate prevails in this basin, with regional average annual temperature of $14^{\circ} \mathrm{C}$ and precipitation of $806 \mathrm{~mm}$.

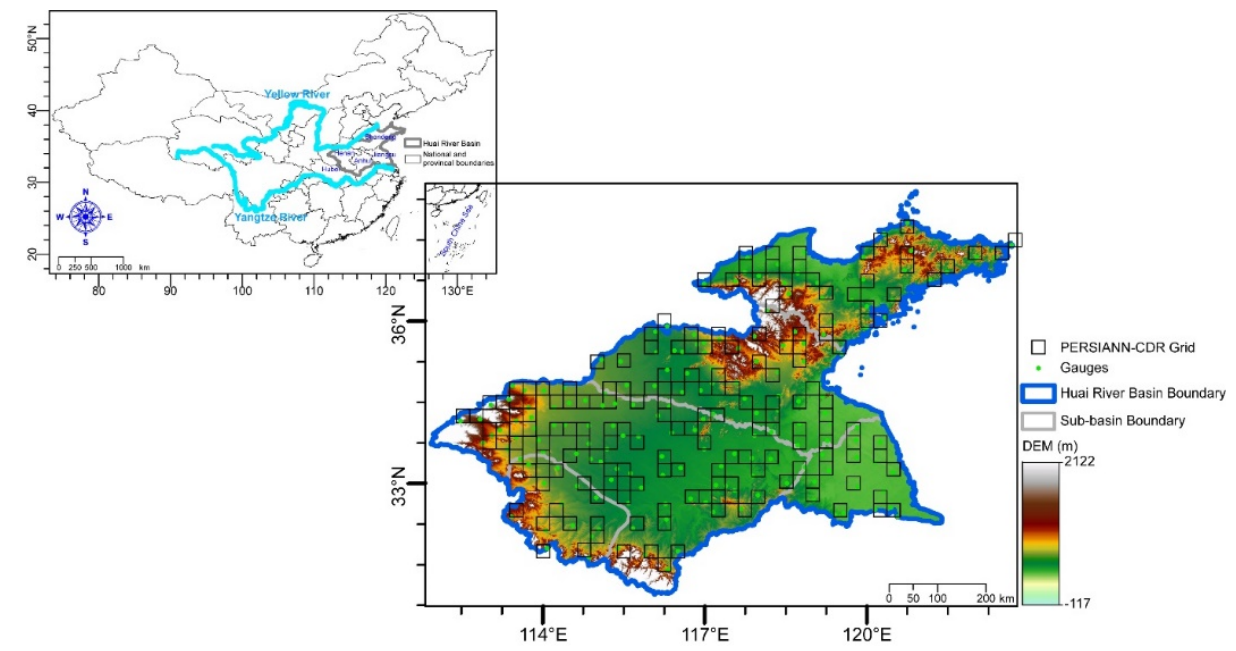

Figure 1. Location of the HRB with gauges and PERSIANN-CDR grids. The digital elevation model (DEM) with a spatial resolution of $90 \mathrm{~m}$ is from http:/ / srtm.csi.cgiar.org/ (accessed on 1 January 2021).

The daily PERSIANN-CDR product has near-global $\left(60^{\circ} \mathrm{S}-60^{\circ} \mathrm{N}\right)$ coverage with a time span from 1983 to the present and a spatial resolution of $0.25^{\circ} \times 0.25^{\circ}$. It is a new retrospective satellite-based dataset developed by the U.S National Climatic Data Center (NCDC) Climate Data Record program in NOAA [36] and can be downloaded from the U.S NOAA National Centers for Environment Information (NCEI; https:/ / www.ncdc.noaa. 
gov/cdr/atmospheric/precipitation-persiann-cdr, accessed on 1 January 2021) and the Centre for Hydrometeorology and Remote Sensing (CHRS) data portal (http:/ / chrsdata. eng.uci.edu, accessed on 1 January 2021). For this evaluation, daily precipitation observed at more than 200 gauges during 1983-2012 were collected from the China Meteorological Administration (CMA). The basic quality issues within the observation precipitation data, e.g., sensors and measurement errors and inherent errors in measurement procedures and methods [37-39], were solved by the CMA. However, it should be noted that data quality issues of missing values and inhomogeneity (e.g., inhomogeneity due to changes in measurement procedures, methods, and locations [36-38]) within observations still remained, and thus we preprocessed the observation data following the procedures below. Firstly, we determined days with missing values for each year and each site. Sites with data available for more than 330 days per year were retained, and missing values of these sites were filled with data from nearby sites by bilinear regression. Subsequently, time series homogeneity was examined with the Pettitt test [40], and the sites with time series not passing the significance test $(p<0.05)$ were removed. Finally, 182 sites remained (Figure 1). To match the PERSIANN-CDR data, we followed Katiraie-Boroujerdy et al. [41] and gridded the sites into grids with a resolution $0.25^{\circ} \times 0.25^{\circ}$ (Figure 1). The final observational value for a certain grid was calculated by averaging daily records of the gauge(s) within this grid. Here, the study period is 1983-2012, considering the data availability of both the PERSIANN-CDR and observations.

\subsection{Methodology}

\subsubsection{Extreme Precipitation Index}

Due to a lack of a unified definition of extreme event indicators in different regions, further research of global extreme weather and climate events has been hindered to some extent. For addressing this issue, the World Meteorological Organization (WMO) and the World Climate Research Program (WCRP) jointly established the Expert Team on Climate Change Detection and Indices (ETCCDI) in the early 21st century and defined a series of climate indices to study extreme climate change globally and regionally. Since then, the ETCCDI extreme climate indices have been extensively used across the globe [41-46]. In this study, we selected 12 indices to comprehensively evaluate the performance of the PERSIANN-CDR across the HRB. Considering characteristics of extreme precipitation, we categorized the 12 indices into four classes (Table 1), i.e., (1) precipitation amount-based indices, (2) precipitation duration-based indices, (3) precipitation frequency-based indices, and (4) precipitation intensity-based indices.

\subsubsection{Validation Metrics}

To quantitatively evaluate the performance of PERSIANN-CDR data, we selected a relatively new, widely-used validation metric, the Kling-Gupta Efficiency (KGE; [33]), which can be used to measure overall performance. The equations can be expressed as

$$
\begin{gathered}
K G E=1-\sqrt{(R-1)^{2}+(\beta-1)^{2}+(\gamma-1)^{2}}, \\
R=\frac{\sum_{i=1}^{N}\left(S_{i}-\mu_{s}\right)\left(O_{i}-\mu_{o}\right)}{\sqrt{\sum_{i=1}^{N}\left(S_{i}-\mu_{s}\right)^{2}} \sqrt{\sum_{i=1}^{N}\left(O_{i}-\mu_{o}\right)^{2}}}, \\
\beta=\frac{\mu_{s}}{\mu_{0}}, \\
\gamma=\frac{\sigma_{s} / \mu_{s}}{\sigma_{0} / \mu_{0}},
\end{gathered}
$$

where $S_{i}$ is the PERSIANN-CDR precipitation value of the $i$ th data pair, and $O_{i}$ is the observational value. $\mu_{s}$ and $\mu_{o}\left(\sigma_{s}\right.$ and $\sigma_{o}$ ) are means (standard deviations) of PERSIANNCDR and observational precipitation, respectively. KGE ranges between $-\infty$ and 1 , of which 
1 implies a perfect overall performance. $R$ is the correlation coefficient. $\beta$ measures the average tendency of PERSIANN-CDR precipitation to be larger (i.e., $\beta>1$ ) or smaller (i.e., $\beta<1$ ) than the observation, with an optimal value of 1 . Regarding $\gamma$, its optimal value of 1 represents that the PERSIANN-CDR can perfectly reproduce the observational precipitation variability, while values below and above 1 , respectively, indicate the underestimated and overestimated variability. After calculating these metrics at each grid with the above equations, their spatial maps were drawn using the ArcGIS 10.2 software package for conveniently comparing the PERSIANN-CDR performance at space.

Table 1. Definitions of the selected 12 extreme precipitation indices.

\begin{tabular}{|c|c|c|c|}
\hline Class & Name & Definition & Unit \\
\hline \multirow{4}{*}{ Precipitation amount-based indices } & PRCPTOT & $\begin{array}{l}\text { Total precipitation on days with precipitation } \\
\qquad \geq 1 \mathrm{~mm}\end{array}$ & $\mathrm{~mm}$ \\
\hline & R85p & $\begin{array}{l}\text { Total precipitation due to events exceeding the } \\
\text { 85th percentile of the study period }\end{array}$ & $\mathrm{mm}$ \\
\hline & R95p & $\begin{array}{l}\text { Total precipitation due to events exceeding the } \\
\text { 95th percentile of the study period }\end{array}$ & $\mathrm{mm}$ \\
\hline & R99p & $\begin{array}{l}\text { Total precipitation due to events exceeding the } \\
\text { 99th percentile of the study period }\end{array}$ & $\mathrm{mm}$ \\
\hline \multirow[t]{2}{*}{ Precipitation duration-based indices } & CDD & $\begin{array}{l}\text { Consecutive dry days. Maximum number of } \\
\text { consecutive dry days (i.e., when precipitation } \\
\qquad<1 \mathrm{~mm})\end{array}$ & days \\
\hline & CWD & $\begin{array}{l}\text { Consecutive wet days. Maximum number of } \\
\text { consecutive wet days (i.e., when precipitation } \\
\qquad \geq 1 \mathrm{~mm})\end{array}$ & days \\
\hline \multirow{3}{*}{ Precipitation frequency-based indices } & $\mathrm{R} 10 \mathrm{~mm}$ & Number of days with precipitation $\geq 10 \mathrm{~mm}$ & days \\
\hline & $\mathrm{R} 20 \mathrm{~mm}$ & Number of days with precipitation $\geq 20 \mathrm{~mm}$ & days \\
\hline & Rnnmm & $\begin{array}{l}\text { Number of days with precipitation } \geq \mathrm{nn} \mathrm{mm} \\
\qquad(\mathrm{nn}=40 \mathrm{~mm} \text { here })\end{array}$ & days \\
\hline \multirow[b]{3}{*}{ Precipitation intensity-based indices } & Rx1day & Maximum 1-day precipitation total & $\mathrm{mm} /$ day \\
\hline & Rx5day & Maximum 5-day precipitation total & $\mathrm{mm} /(5$ days $)$ \\
\hline & SDII & $\begin{array}{l}\text { Simple daily intensity index Total precipitation } \\
\text { divided by the number of wet days (i.e., average } \\
\text { precipitation of the days with precipitation } \\
\geq 1 \mathrm{~mm} \text { ) }\end{array}$ & $\mathrm{mm} /$ day \\
\hline
\end{tabular}

\section{Results}

\subsection{Evaluation of Precipitation Amount-Based Indices}

Multi-year annual PRCPTOT, R85p, R95p, and R99p from observational precipitation were generally characterized by a decrease from southeastern to northwestern, with the HRB means of $812.60 \mathrm{~mm}, 441.15 \mathrm{~mm}, 233.68 \mathrm{~mm}$, and $76.64 \mathrm{~mm}$, respectively (Figure 2a1-a4). Overall, the PERSIANN-CDR could capture a similar spatial distribution for each amountbased index, with spatial Rs of 0.94 for PRCPTOT, 0.92 for R85p, 0.89 for R95p, and 0.81 for R99p (Figure 2b1-b4). Despite that, evident differences in the climatological values of these amount-based indices existed between observation and PERSIANN-CDR (Figure 2b1-b4); the HRB $\beta>1.0$ indicated that the PERSIANN-CDR overestimated the climatological values of the amount-based indices. Meanwhile, the spatial variabilities of the climatological values were all overestimated, with HRB $\gamma$ values of 1.40, 1.32, 1.45, and 1.56 for PRCPTOT, R85p, R95p and R99p, respectively. To have an integrative consideration of $\beta, \gamma$, and $R$, the PERSIANN-CDR showed high (i.e., KGEs $\geq 0.38$ ) performance overall in spatially representing the climatological value of each amount-based index, especially for R95p with a KGE of 0.58 . 

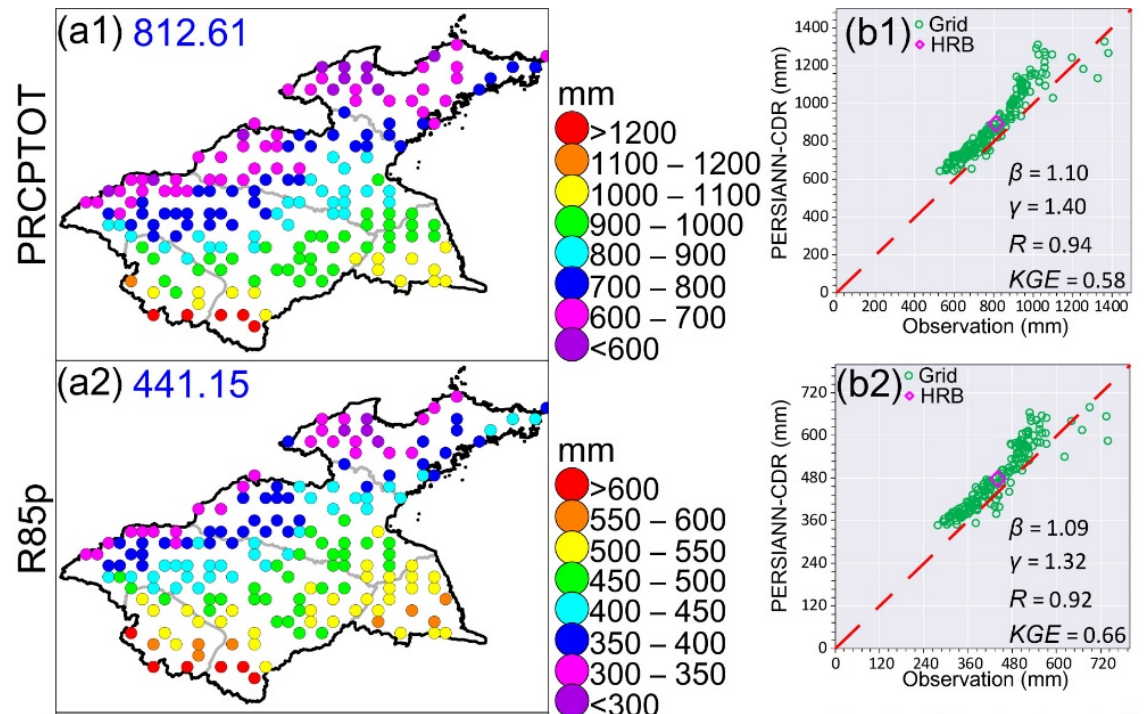

$>600$

$550-600$

$500-550$

$450-500$

$400-450$

$350-400$

$300-350$
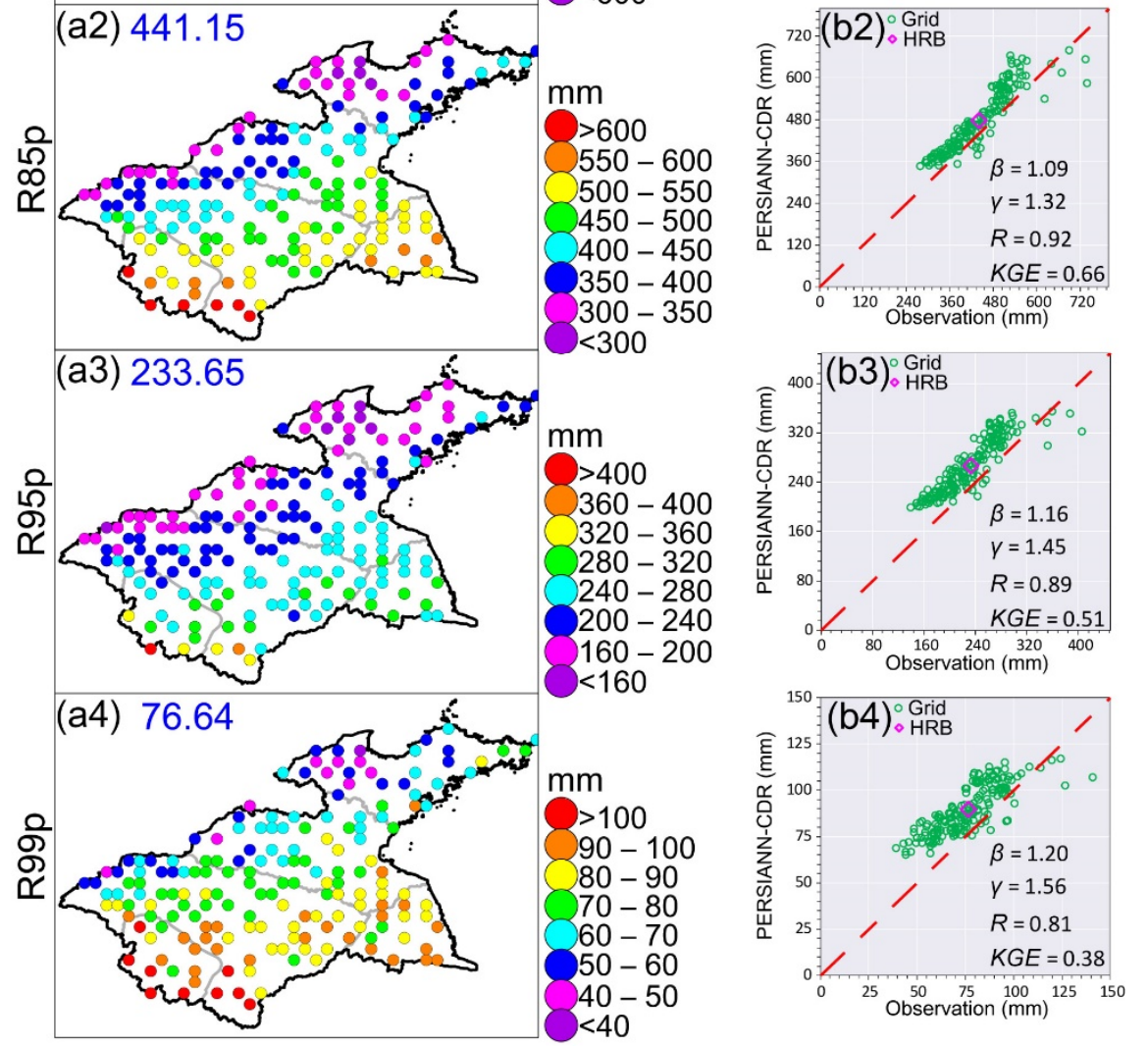

Figure 2. Spatial patterns of multi-year annual means of observational amount-based indices and the scatterplots between observation and PERSIANN-CDR. a1-a4 (b1-b4) are for PRCPTOT, R85p, R95p, and R99p, respectively. In a1-a4, the blue numbers represent the HRB mean for a given extreme precipitation index. The red dashed line within $\mathbf{b} \mathbf{1}-\mathbf{b} 4$ is the 1:1 line.

Generally, each of the four amount-based indices was differently overestimated at $>90 \%$ of grids by the PERSIANN-CDR (Figure 3a1-a4). Larger overestimations (i.e., $\beta>1.4$ ) for PRCPTOT and R85p were mainly located in the southern part (Figure 3a1,a2), while for R95p and R99p larger overestimations were widely distributed across the HRB except for small part of southern HRB (Figure 3a3,a4). For PRCPTOT (R85p), $\gamma$ values were between 1.0 and 1.2 at $>90 \%$ of grids, corresponding to overestimated temporal variability; generally, in southwestern and easternmost HRB, temporal variability at $<10 \%$ of grids was underestimated (Figure 3b1,b2). Regarding R95p and R99p (Figure 3b3,b4), overestimated temporal variabilities existed at $>90 \%$ of grids, of which $>30 \%$ of grids had $\gamma>1.2$, mainly in the central-northern part for R95p and in the northern and southeastern parts for R99p. Checking temporal $R \mathrm{~s}$ for PRCPTOT at all the grids (Figure 3c1), the values were all $>0.50$, with $81 \%$ of grids showing Rs $>0.70$ widely distributed across the HRB. As for R85p (Figure $3 \mathrm{c} 2$ ), most (>85\%) grids showed temporal Rs $>0.50$, especially for western, southeastern, and northeastern HRB, with temporal Rs $>0.70$, while it was noted that there were still some grids with $R \mathrm{~s}<0.40$ sporadically in the central-northern part. Seen in Figure 3c3, $50 \%$ of grids showed $R \mathrm{~s}>0.50$ for R95p, accompanied by $<10 \%$ of grids with $R \mathrm{~s}>0.70$ in 
southwestern HRB; of the remaining grids, their corresponding $R \mathrm{~s}<0.2$ indicated that the PERSIANN-CDR had much limited ability in reproducing temporal fluctuations of R95p. Figure $3 c 4$ illustrates that the PERSIANN-CDR could capture temporal fluctuations of R99p at only $15 \%$ of grids, mainly in western HRB; moreover, negative Rs in northeastern HRB suggested that the product had no capacity in reproducing temporal fluctuations of R99p. At $>90 \%$ of grids, KGEs for both PCPTOT and R85p were $>0.20$, especially in centralnorthern HRB, with KGEs $>0.40$ indicating better overall performance (Figure 3d1,d2). For R95p (Figure 3d3), there existed $66 \%$ of grids with KGEs $>0.2$, particularly those in the southern part with KGEs > 0.40, whereas in the northern part around $30 \%$ of grids with $K G E s<0.20$ showed limited overall performance for representing R95p. Except for the 16\% of grids in the southwestern part with KGEs between 0.2 and 0.4 , the PERSIANN-CDR lacked the ability to represent R99p over the remaining grids (Figure 3d4).

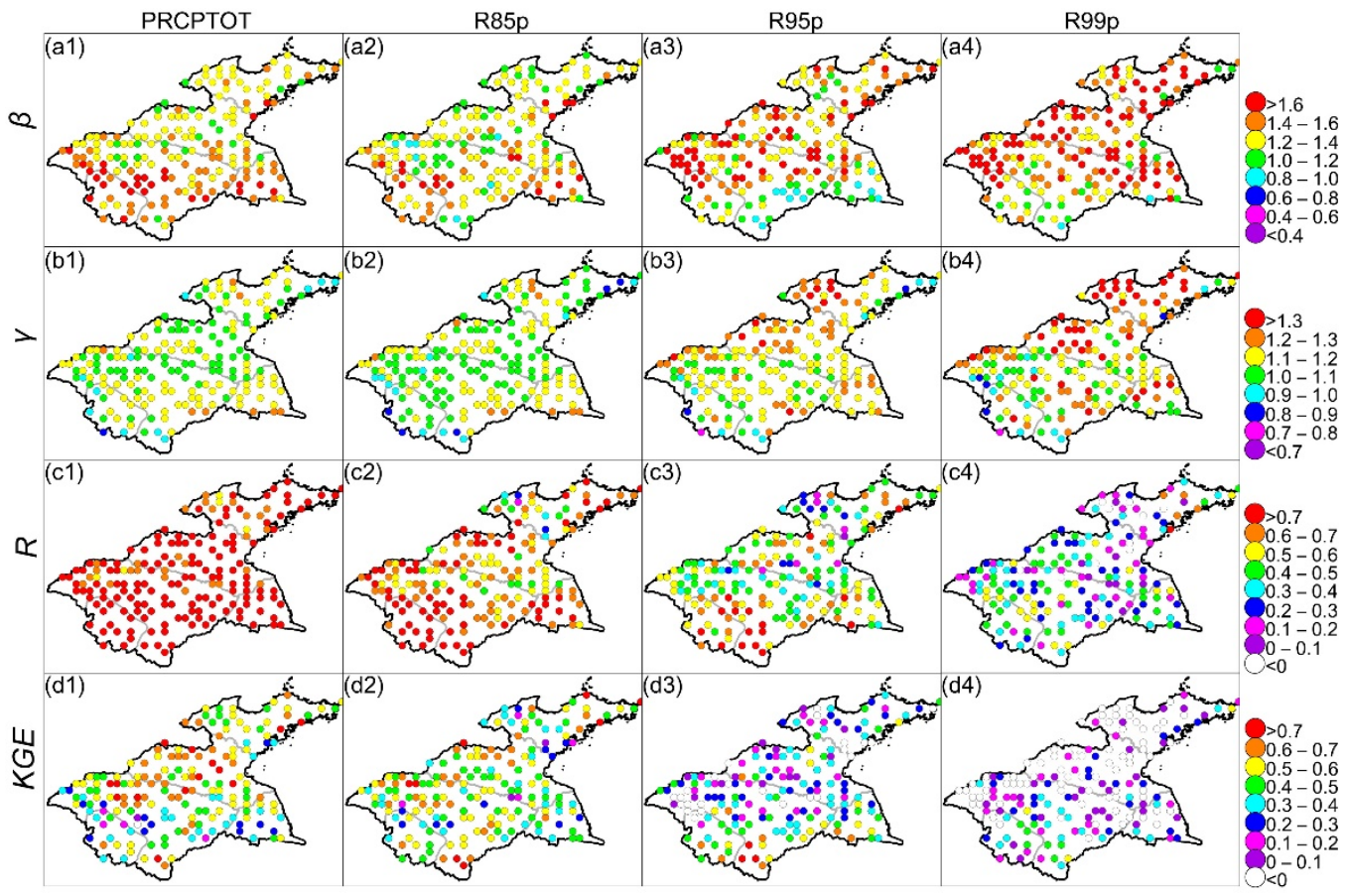

Figure 3. Spatial patterns of different validation metrics for the amount-based indices.

At space, the observational PRCPTOT, R85p, R95p, and R99p trends had a similar distribution, i.e., decreased over western and southeastern parts, but increased in other regions, with the $\mathrm{HRB}$ trends of $4.17 \mathrm{~mm} / \mathrm{yr}, 3.68 \mathrm{~mm} / \mathrm{yr}, 3.13 \mathrm{~mm} / \mathrm{yr}$, and $1.69 \mathrm{~mm} / \mathrm{yr}$, respectively (Figure $4 \mathrm{a} 1-\mathrm{a} 4$ ). Moreover, the percentage of the grids with positive trends for each index was always $\geq 56 \%$. As shown in Figure $4 b 1-b 4$, each of the PERSIANNCDR amount-based indices corresponded to underestimated trends at most $(>50 \%)$ grids; for the regional mean, the HRB $\beta<0.5$ suggested that the PERSIANN-CDR seriously underestimated the trends of these amount-based indices, especially for the PRCPTOT with opposite changes (i.e., $\beta=-0.18$ ) between the observation and the PERSIANNCDR. Except for PRCPTOT, the spatial variabilities of R85p, R95p, and R99p trends were overestimated with the HRB $\gamma$ values $>1.00$. The PERSIANN-CDR showed a moderate performance (spatial $R=0.39$ ) in producing spatial patterns of PRCPTOT trends, but much limited capacity (spatial Rs $<0.20$ ) existed for the other three indices. Based on $K G E$, it is evident that the PERSIANN-CDR had no ability (i.e., KGEs $<0$ ) to present the trends of these amount-based indices. 

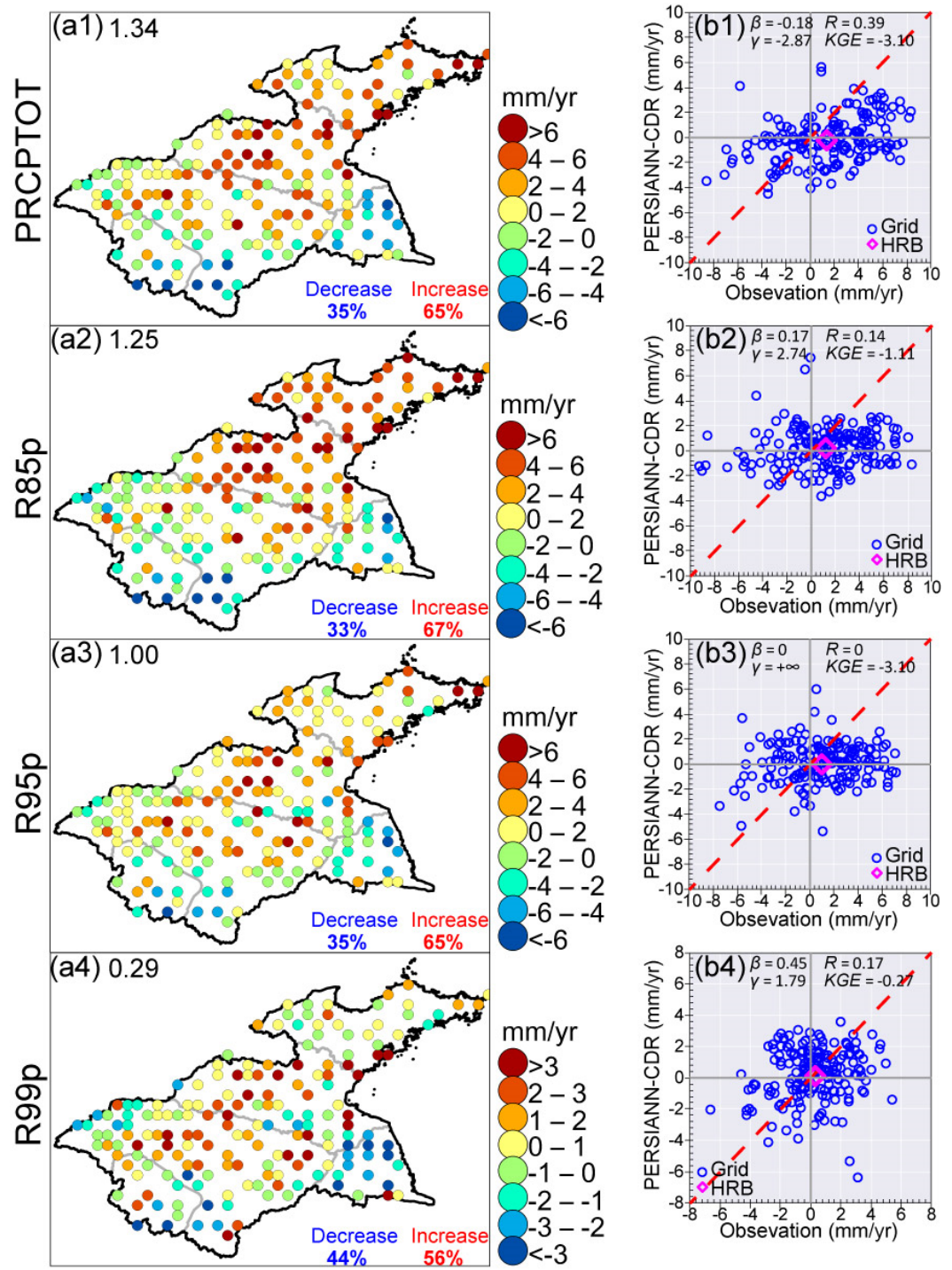

Figure 4. Spatial patterns of the temporal trends of the observational amount-based indices (a1-a4), and the scatterplots between observation and PERSIANN-CDR. a1-a4 (b1-b4) are for PRCPTOT, R85p, R95p, and R99p, respectively. In a1-a4, the black numbers represent the HRB trends of the observational amount-based indices, while the blue (red) numbers indicate grid percentages with increasing (decreasing) trend across the HRB. The red dashed line in $\mathbf{b} 1-\mathbf{b} 4$ is the 1:1 line.

\subsection{Evaluation of Precipitation Duration-Based Indices}

For the HRB, the observational multi-year annual means of CDD and CWD were 45.22 days and 5.08 days, respectively (Figure 5a1,a2), corresponding to spatial distributions of a decrease from northwest to southeast and an increase from northwest to southeast. Based on spatial Rs of 0.86 for CDD and 0.71 for CWD (Figure 5b1,b2), the PERSIANN-CDR better detected spatial distributions of climatological characteristics of these two durationbased indices. It is evident that for the HRB, the PERSIANN-CDR seriously underestimated and overestimated magnitudes of climatological CDD and CWD values, respectively, with $\beta$ values of 0.68 and 1.95 (Figure 5b1,b2). For spatial variability, larger overestimation existed for CDD with the HRB $\gamma$ of 1.44, while CWD corresponded to a slight underestimation $(\gamma=0.98)$. In terms of $K G E$, this PERSIANN-CDR had no ability to represent CWD, while better overall performance $(K G E=0.44)$ existed for CDD (Figure $5 b 1, b 2)$. 

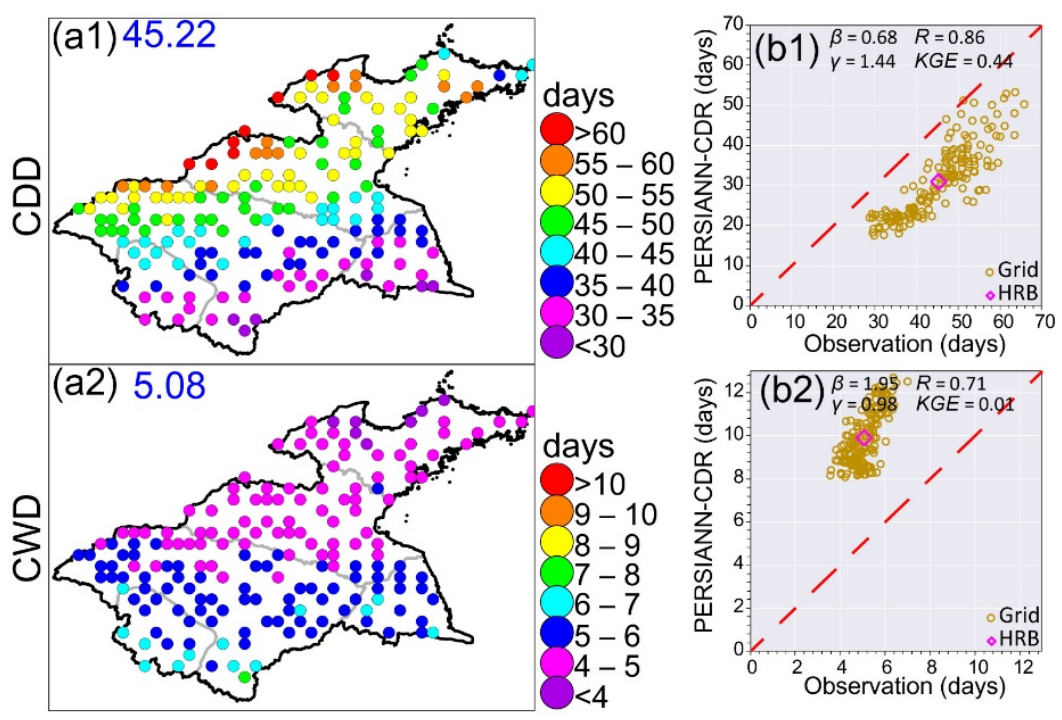

Figure 5. Spatial patterns of multi-year annual means of observational duration-based indices and the scatterplots between observation and PERSIANN-CDR. a1,a2 (b1,b2) are for CDD and CWD, respectively. In $\mathbf{a 1}, \mathbf{a} 2$, the blue numbers represent the HRB mean for a given extreme precipitation index. The red dashed line in $\mathbf{b} \mathbf{1}, \mathbf{b} \mathbf{2}$ is the $1: 1$ line.

At all the grids, CDD were underestimated $(\beta<1.00)$, followed by $>95 \%$ of grids with larger underestimations $(\beta<0.80)$ (Figure 6a1). Conversely, the PERSIANN-CDR much overestimated CWD $(\beta>1.40)$ across the HRB (Figure 6a2). Based on $\gamma$, temporal variabilities of CDD were underestimated at $>90 \%$ of grids (Figure $6 \mathrm{~b} 1$ ), and larger underestimations $(\gamma<0.9)$ mainly appeared in western HRB, followed by some grids with overestimations $(\gamma>1.00)$, mainly in some parts of eastern HRB. For CWD (Figure 6b2), overestimations (underestimations) of temporal variabilities occurred at $25 \%(75 \%)$ of grids but were characterized by sporadic distribution across the study region. Regarding CDD (Figure $6 \mathrm{c} 1)$, the PERSIANN-CDR had strong ability $(R>0.50)$ to represent temporal fluctuations at $40 \%$ of grids in northwestern HRB, but moderate or limited ability at other grids. Except for only $5 \%$ of grids with a certain capacity, the PERSIANN-CDR had limited or no capacity $(R<0.20)$ in reproducing temporal fluctuations of CWD across the HRB (Figure 6c2). Seen in Figure 6d1, the PERSIANN-CDR had the ability (KGE $>0.30$ ) to represent $\mathrm{CDD}$ at $>60 \%$ of grids in northern HRB, followed by no ability, mainly in southern HRB. Smaller (near to 0 ) and negative KGEs at all the grids suggested the PERSIANN-CDR had no ability in capturing CWD across the HRB (Figure 6d2).

In view of observations, the two duration-based indices for the HRB differently increased, with a rate of 0.24 days/yr for CDD and 0.02 days/yr for CWD (Figure 7a1,a2). Spatially, the positive trends of the observational CDD occurred at $84 \%$ of grids, followed by decreasing trends at $16 \%$ of grids in central-northern and southwestern parts (Figure 7a1). There existed $>30 \%$ of grids with decreased CWD, generally in western HRB, while increased CWD was widely distributed across eastern HRB, with a grid percentage around $70 \%$ (Figure 7a2). For the HRB, the CDD trends were overestimated by the PERSIANN$\mathrm{CDR}$, with $\beta$ of 1.20 (Figure $7 \mathrm{~b} 1$ ), while the product seriously underestimated $(\beta=0.12)$ the CWD trends (Figure $7 \mathrm{~b} 2$ ). In terms of $\gamma$, the PERSIANN-CDR overestimated spatial variabilities of both CDD and CWD trends, especially for CWD, with a serious overestimation $(\gamma=10.58)$ (Figure $7 \mathrm{~b} 1, \mathrm{~b} 2)$. Overall, there was no ability $(R<0.10)$ for the PERSIANN-CDR to produce spatial patterns of the trends of the duration-based indices, accompanied by no $K G E$-based ability (KGE near to 0 and even $<0$ ) (Figure $7 \mathrm{~b} 1, \mathrm{~b} 2$ ). 


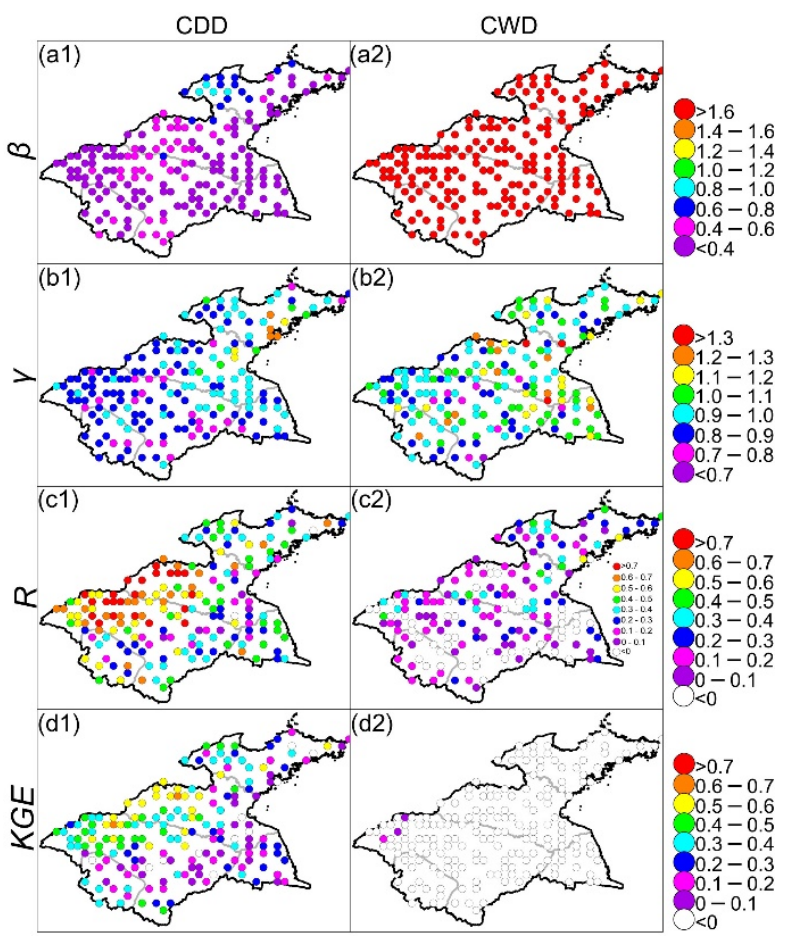

Figure 6. Spatial patterns of different validation metrics for the duration-based indices.
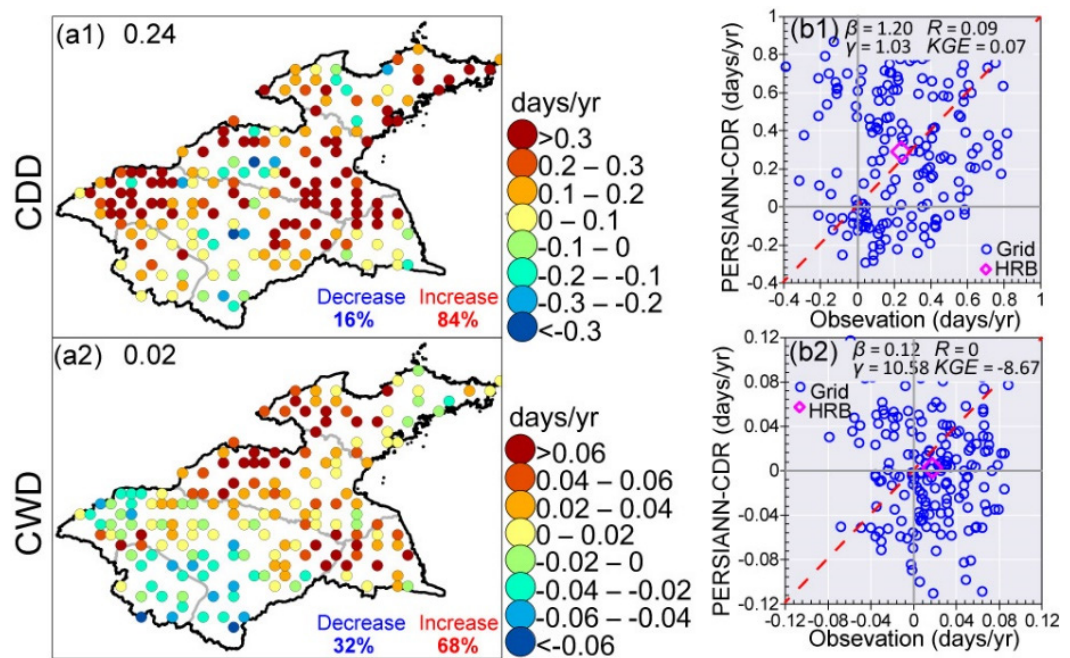

Figure 7. Spatial patterns of the temporal trends of the observational duration-based indices and the scatterplots between observation and PERSIANN-CDR. a1,a2 $(\mathbf{b 1} \mathbf{1} \mathbf{b} 2)$ are for CDD and CWD, respectively. In a1,a2, the black numbers represent the HRB trends of the observational durationbased indices, while the blue (red) numbers indicate grid percentages with increasing (decreasing) trend across the HRB. The red dashed line in $\mathbf{b} \mathbf{1}, \mathbf{b} \mathbf{2}$ is the $1: 1$ line.

\subsection{Evaluation of Precipitation Frequency-Based Indices}

Multi-year annual R10mm, R20mm, and Rnnmm from observational precipitation were characterized by a decrease from northwest to southeast, with the HRB means of 22.93 days, 11.73 days, and 8.86 days, respectively (Figure 8a1-a3). Overall, the PERSIANN-CDR could better capture spatial distributions of climatological R10mm, R20mm, and Rnnmm, with spatial Rs of 0.96, 0.91, and 0.90, respectively (Figure 8b1-b3). For the HRB, magnitudes and spatial variabilities for climatological value of each frequency index were differently underestimated and overestimated by the PERSIANN-CDR, respectively (Figure 8b1-b3). Specifically, 
the PERSIANN-CDR showed the largest Rnnmm underestimation in magnitude (spatial variability) with the HRB $\beta(\gamma)$ of 0.68 (1.30) (Figure 8b1-b3). Based on KGE, this product had better overall performance (i.e., KGE > 0.55) in representing the three frequency-based indices, particularly for R10mm and R20mm, with KGEs > 0.60 (Figure 8b1-b3).
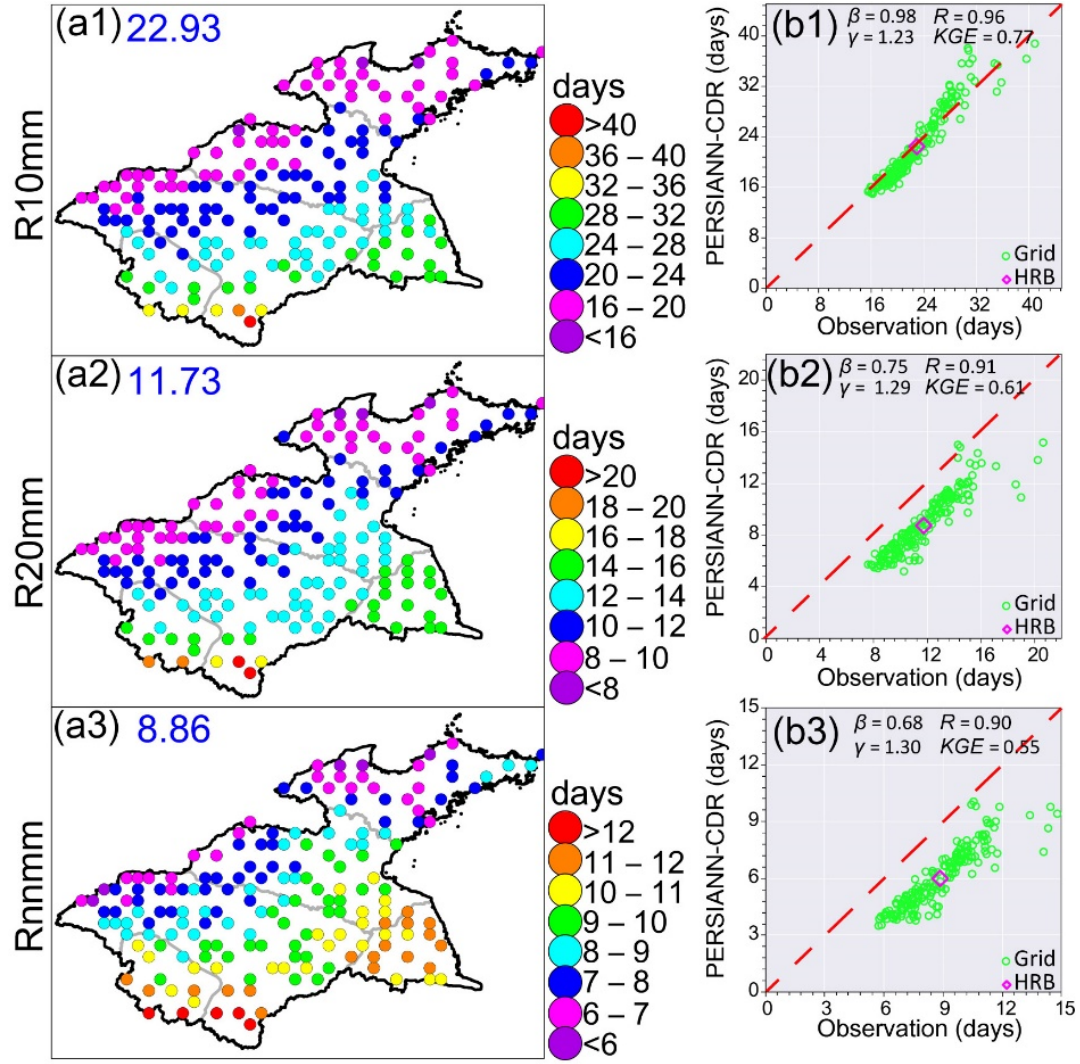

Figure 8. Spatial patterns of multi-year annual means of observational frequency-based indices and the scatterplots between observation and PERSIANN-CDR. a1-a3 (b1-b3) are for R10mm, R20mm, and Rnnmm, respectively. In a1-a3, the blue numbers represent the HRB mean for a given extreme precipitation index. The red dashed line in $\mathbf{b} 1-\mathbf{b} 3$ is the $1: 1$ line.

Seen in Figure 9a1, except for $4 \%$ of grids in the southern part with smaller overestimations ( $\beta$ between 1.00 and 1.10), the PERSIANN-CDR differently underestimated R10mm at the remaining grids. Regarding $\mathrm{R} 20 \mathrm{~mm}$ and $\mathrm{Rnnmm}$, the underestimations $(\beta<1.00)$ occurred at an overwhelming majority ( $>98 \%$ ) of grids, of which $>80 \%$ of grids corresponded to larger underestimations $(\beta<0.60)$ (Figure 9a2,a3). Based on $\gamma$, temporal variabilities of the three frequency-based indices were differently underestimated at $>75 \%$ of grids (Figure 9b1-b3); larger underestimations $(\gamma<0.8)$ for R20mm in northern HRB and for Rnnmm in northern and central-southern parts (Figure 9b2,b3). Moreover, there were some grids with overestimated temporal variabilities $(\gamma>1.00)$ of the frequency-based indices, e.g., R10mm and R20mm at $>15 \%$ of grids, generally in southern HRB (Figure 9b1,b2). It is evident that the PERSIANN-CDR had strong ability $(R>0.50)$ to represent temporal fluctuations of R10mm at $89 \%$ of grids, which were widely distributed across the HRB; for R20mm and Rnnmm, there existed $>50 \%$ of grids with $R>0.50$, mainly in southern HRB (Figure 9c1-c3). Obviously, the PERSIANN-CDR exhibited a better overall performance $(K G E>0.40)$ in detecting R10mm at all the grids (Figure 9d1). Except for $<15 \%$ of grids, generally in northwestern and northeastern HRB with no estimation ability, southern HRB corresponded to KGEs > 0.20 for Rn20mm and Rnnmm (Figure 9d2,d3), particularly for most grids of southern HRB, with KGEs $>0.5$. 


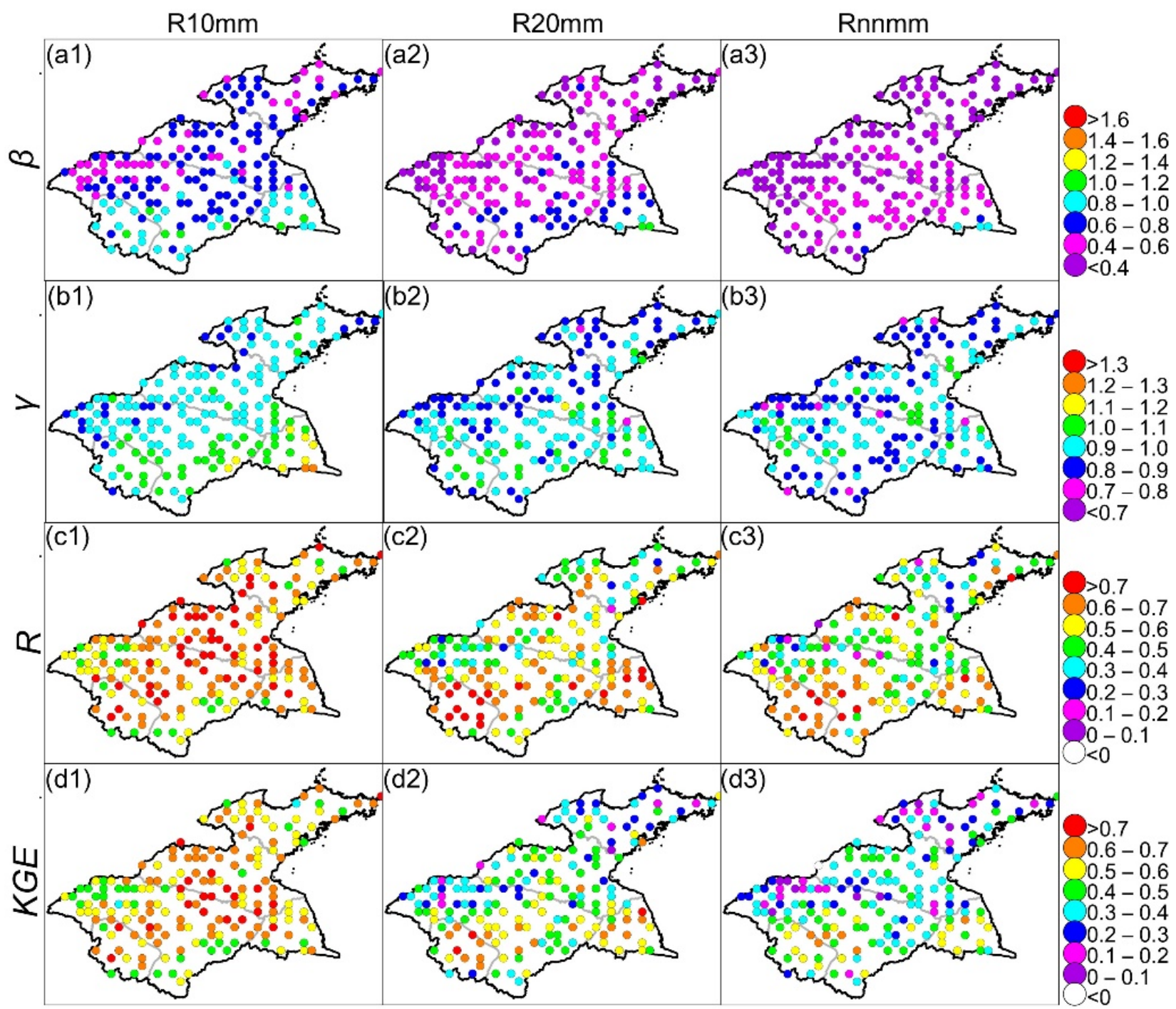

Figure 9. Spatial patterns of different validation metrics for the frequency-based indices.

As shown in Figure 10a1-a3, the HRB R10mm, R20mm, and Rnnmm increased by 0.03 days/yr, 0.03 days/yr, and 0.02 days/yr, respectively. At space, the trends of the observational frequency-based indices generally had a decrease in the western part and an increase in eastern parts; moreover, there were always $\geq 65 \%$ of grids with positive trends for the three indices. For the HRB, the PERSIANN-CDR seriously underestimated $(\beta<0.50)$ the trends of all the frequency-based indices, and even for R20mm and Rnnmm, the PERSIANN-CDR showed the opposite trends (Figure 10b1-b3). The metric of $\gamma$ suggested that this product overestimated spatial variabilities of R10mm (Figure 10b1). There was no ability $(R \leq 0.11)$ for the PERSIANN-CDR to produce spatial patterns of R10mm, R20mm, and Rnnmm trends, accompanied by no KGE-based ability $(K G E<0)$ (Figure 10b1-b3). 

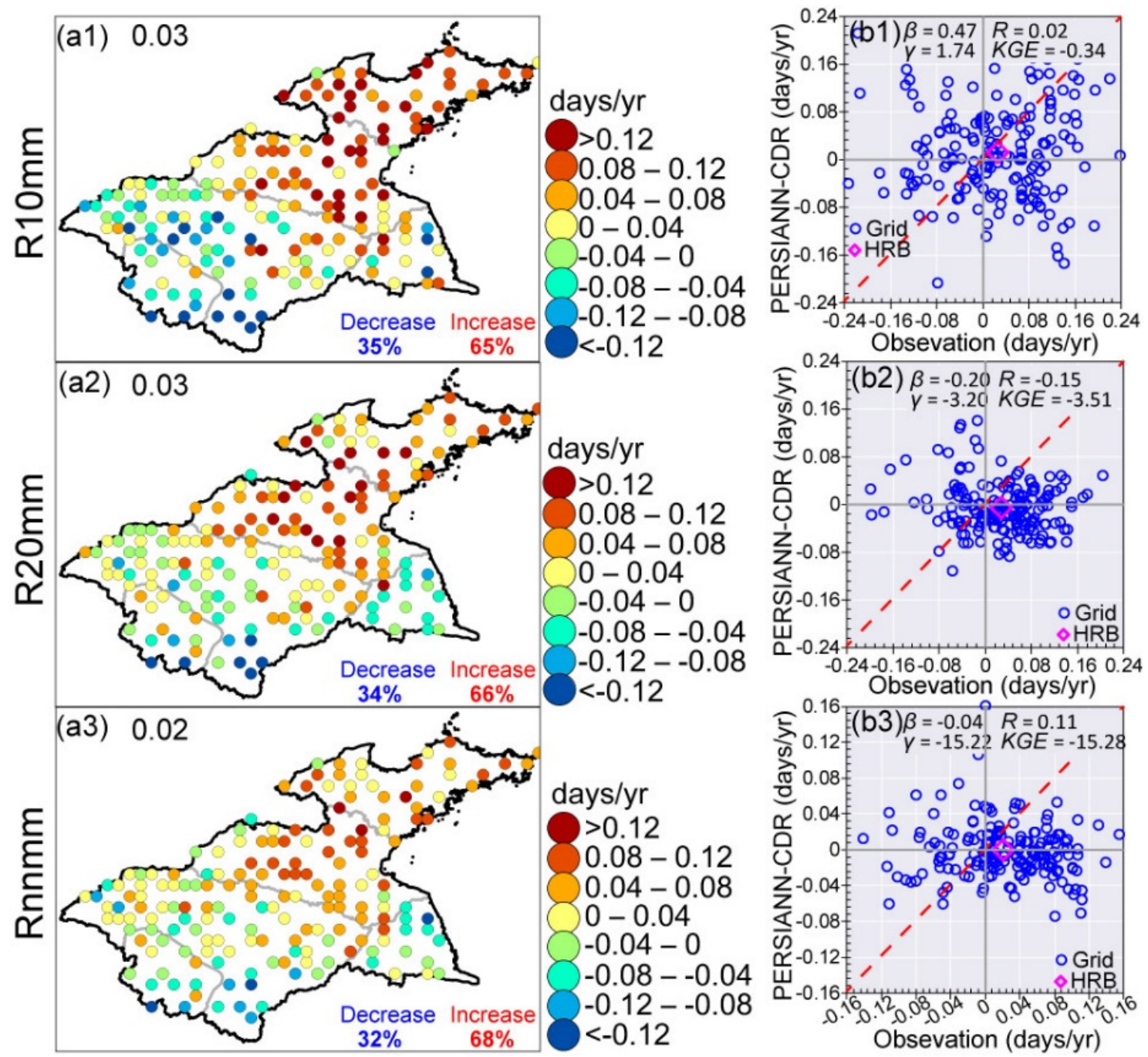

Figure 10. Spatial patterns of the temporal trends of the observational frequency-based indices and the scatterplots between observation and PERSIANN-CDR. a1-a3 (b1-b3) are for R10mm, R20mm, and Rnnmm, respectively. In a1-a3, the black numbers represent the HRB trends of the observational frequency-based indices, while the blue (red) numbers indicate grid percentages with increasing (decreasing) trend across the HRB. The red dashed line in $\mathbf{b} \mathbf{1}-\mathbf{b} 3$ is the 1:1 line.

\subsection{Evaluation of Precipitation Intensity-Based Indices}

For Rx1day, Rx5day, and SDII, the observational multi-year annual means were $96.05 \mathrm{~mm} /$ day, $148.97 \mathrm{~mm} /(5$ days), and $12.99 \mathrm{~mm}$ /day for the HRB, respectively, generally characterized by an increase from the northwest to southeast (Figure 11a1-a3). The spatial Rs of 0.25 for Rx1day, 0.38 for Rx5day, and 0.52 for SDII indicated that the PERSIANN-CDR could reproduce spatial patterns of climatological characteristics of the intensity-based indices (Figure 11b1-b3). The HRB $\beta$ values $<0.80$ for the intensity-based indices suggested that the three indices were underestimated by the PERSIANN-CDR, especially for SDII $(\beta=0.49)$, followed by R1xday $(\beta=0.64)$. For Rx1day and Rx5day, the HRB $\gamma$ values $<1.0$ indicated that spatial variabilities of the two PERSIANN-CDR intensity-based indices were smaller than the observations (Figure 11b1,b2), followed by SDII with $\gamma$ of 1.37. Based on KGE, this product had a moderate overall performance (KGE $>0.20$ ) in representing the three intensity-based indices. 

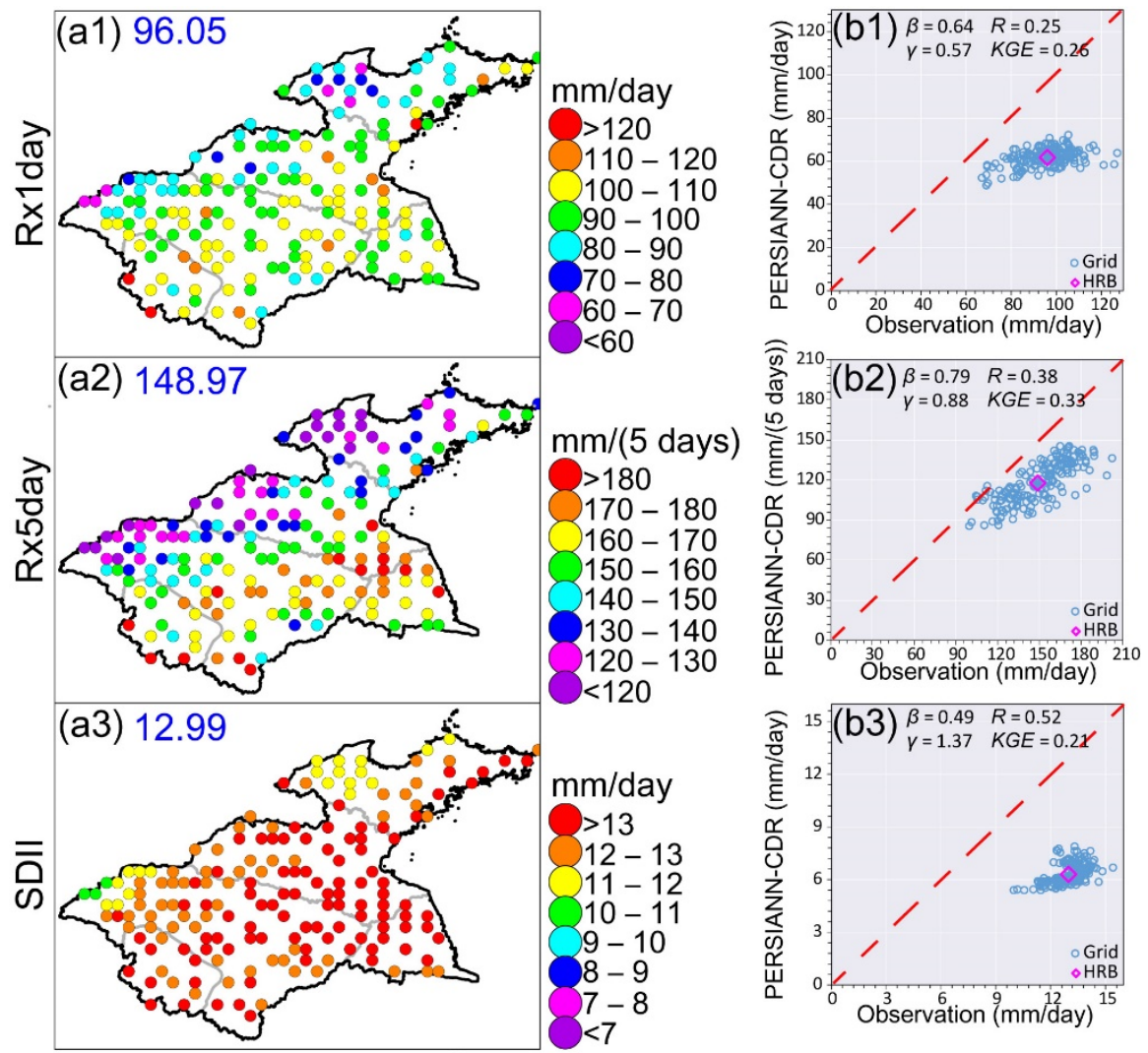

Figure 11. Spatial patterns of multi-year annual means of the observational intensity-based indices and the scatterplots between observation and PERSIANN-CDR. a1-a3 (b1-b3) are for Rx1day, Rx5day, and SDII, respectively. In a1-a3, the blue numbers represent the HRB mean for a given extreme precipitation index. The red dashed line in $\mathbf{b} 1-\mathbf{b} 3$ is the 1:1 line.

In general, the intensity-based indices were underestimated by PERSIANN-CDR except for only $3 \%$ of grids with slight overestimations ( $\beta$ between 1.00 and 1.20 ) for Rx5day in the northeastern part (Figure 12a1-a3). There were more than $80 \%$ of grids with overestimated temporal variabilities for the three indices, especially in northwestern and central-eastern HRB, with $\gamma>1.40$ for Rx1day and Rx5day, and in northwestern and southeastern HRB, with $\gamma>1.30$ for SDII (Figure 12b1-b3). The PERSIANN-CDR had strong or moderate ability $(R>0.30)$ in detecting temporal fluctuations of R1xday at $39 \%$ of grids, but ability was sporadically distributed across the HRB (Figure 12c1). For Rx5day (Figure 12c2), there existed $68 \%$ of grids with $R>0.30$, of which $30 \%$ of grids with better $R$-based performance $(R>0.50)$ were generally in southern HRB; moreover, the PERSIANNCDR showed limited $(R<0.30)$ or no ability in reproducing temporal variability, particularly in the northern part with $R<0.20$ and even negative. For SDII (Figure $12 \mathrm{c} 3$ ), $>90 \%$ of grids with $R>0.30$ suggested that the PERSIANN-CDR had the ability to reproduce temporal variability across the HRB, especially for western and southeastern parts, with better $R$ based performance $(R>0.50)$. Spatially, the product had the ability $(K G E>0.20)$ to represent Rx1day at $28 \%$ of grids, mainly in middle HRB, but no ability at $72 \%$ of grids (Figure $9 \mathrm{~d} 1$ ). With exception of $40 \%$ of grids having no ability, generally in northern HRB, the PERSIANNCDR corresponded to a better overall performance for Rx5day across southern HRB, especially in the southeastern part, with KGE $>0.40$ (Figure 9d2). The PERSIANN-CDR exhibited a certain overall performance $(K G E>0.20)$ in detecting SDII at $59 \%$ of grids, followed by $41 \%$ of grids with limited and even no ability (Figure 12d3). 


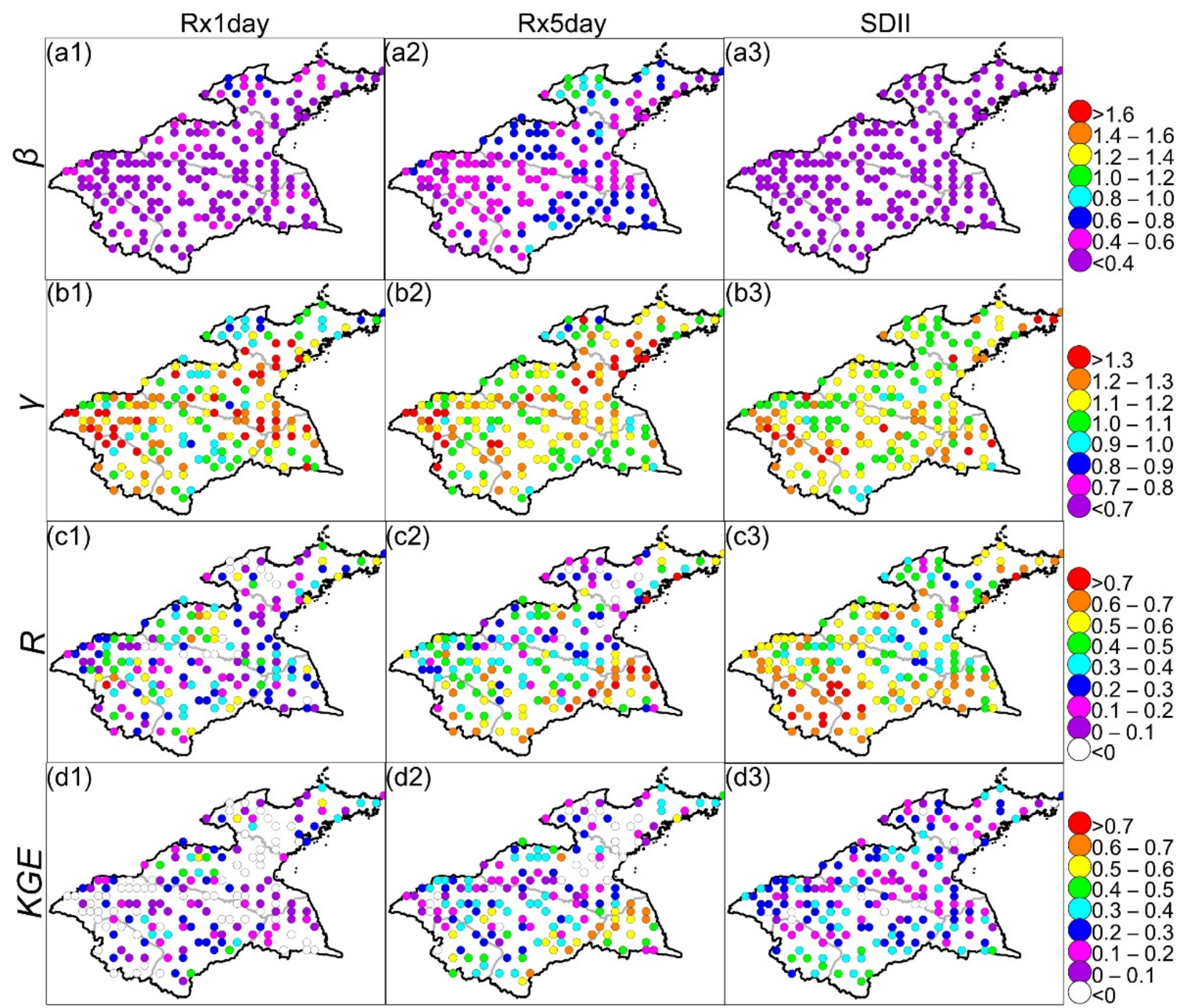

Figure 12. Spatial patterns of different validation metrics for the intensity-based indices.

All the observational precipitation intensity-based indices for the HRB increased but at different rates, i.e., $0.23 \mathrm{~mm} /$ (day yr) for Rx1day, $0.76 \mathrm{~mm} /(5$ days yr) for Rx5day, and $0.03 \mathrm{~mm} /($ day yr) for SDII (Figure 13a1-a3). Generally, the measured Rx1day increased at most (59\%) grids, followed by $41 \%$ of grids with decreased Rx1day, while the spatial distribution was scattered (Figure 13a1). For the observational Rx5day, 74\% of grids corresponded to an increase, particularly in western HRB (excluding southwestern part) with a rate $1.00 \mathrm{~mm} /(5$ days yr), while the remaining grids, generally in the southwestern and southeastern parts, showed different reductions (Figure 13a2). There were $34 \%$ of grids with decreased SDII, mainly in the southwestern and southeastern parts, followed by increases at the remaining grids (Figure 13a3). Broadly, the HRB $\beta$ values for the intensity-based indices were all $\leq 0.52$, suggesting underestimated trends by the PERSIANN-CDR, especially for Rx5day trends, with many underestimations $(\beta=0.20)$ (Figure 13b1-b3). In terms of the HRB $\gamma$, the PERSIANN-CDR underestimated spatial variabilities $(\gamma<0.90)$ for the HRB Rx1day and SDII trends but overestimated $(\gamma<1.31)$ Rx5day trends (Figure 10b1-b3). The PERSIANN-CDR had a certain $R$-based performance (spatial $R$ around 0.20 or $>0.30$ ) in producing spatial patterns of these indices' trends (Figure 13b1-b3). There was no ability $(K G E<0.10)$ for the PERSIANN-CDR to represent these trends (Figure 10b1-b3). 

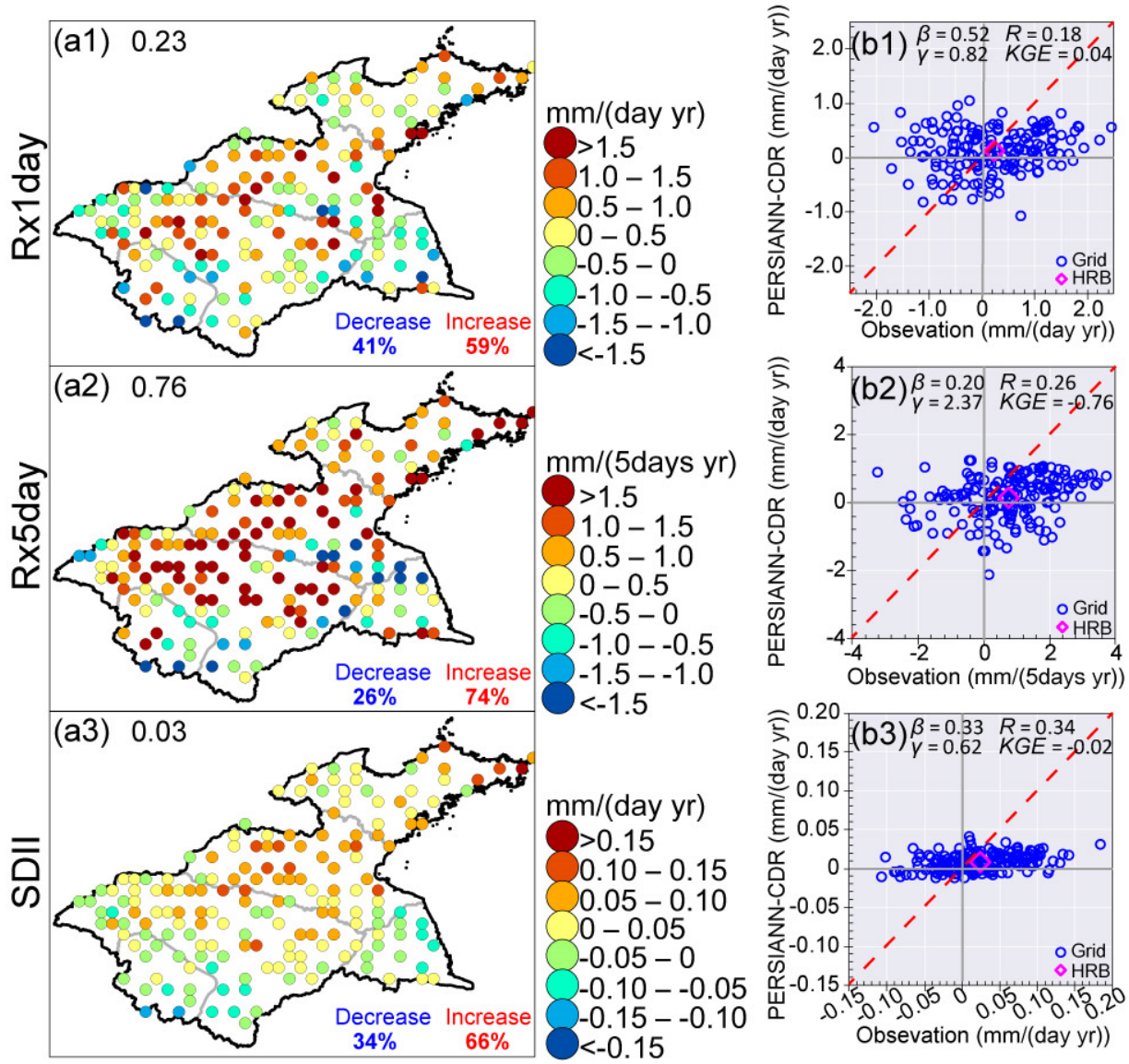

Figure 13. Spatial patterns of the temporal trends of the observational intensity-based indices and the scatterplots between observation and PERSIANN-CDR. a1-a3 (b1-b3) are for Rx1day, Rx5day, and SDII, respectively. In a1-a3, the black numbers represent the HRB trends of the observational intensity-based indices, while the blue (red) numbers indicate grid percentages with increasing (decreasing) trend across the HRB. The red dashed line in b1-b3 is the 1:1 line.

\section{Conclusions and Discussion}

Attempts to validate various satellite-based precipitation products' capacity in representing precipitation characteristics from different perspectives have been widely conducted all over the world. However, information about their capacity in detecting extreme precipitation and related changes (i.e., linear trends) is scarce. As a result, we collected daily observations from 182 gauges across the HRB during 1983-2012 and examined the PERSIANN-CDR capacity to represent precipitation amount- (PRCPTOT, R85p, R95p, and R99p), duration- (CDD and CWD), frequency- (R10mm, R20mm, and Rnnmm), and intensity-based (Rx1day, R5xday, and SDII) indices and their linear trends. The conclusions can be summarized as follows.

(1) Validation for amount-based indices. Overall, the PERSIANN-CDR could well capture climatological characteristics of the amount-based indices, but with overestimations in magnitudes and spatial variabilities for the HRB. At most grids, both magnitudes and temporal variabilities of each amount-based index were differently overestimated. Generally, the PERSIANN-CDR had better $R$ - and KGE-based performance in producing the amount-based indices (excluding R99p) across the HRB. The linear trend of each amount-based index was underestimated at most grids. Except for PRCPTOT, overestimations (limited capacity) existed for spatial variabilities (spatial patterns) of the other indices' trends. Broadly, the PERSIANN-CDR had no KGE-based ability to present the trends of the four indices.

(2) Validation for duration-based indices. Though the PERSIANN-CDR better detected spatial distributions of climatological characteristics of the duration-based indices, 
it underestimated and overestimated climatological values of the HRB CDD and CWD, respectively. For spatial variabilities, overestimations existed for the climatological CDD, but underestimations for the climatological CWD. The PERSIANN-CDR showed no KGE-based ability and better overall performance in representing the climatological CWD and CDD, respectively. Over most of the HRB, CDD (CWD) were underestimated (overestimated), with underestimations of temporal variabilities. For most grids, the PERSIANN-CDR had strong and moderate ability to represent temporal fluctuations of CDD, with moderate KGE-based performance; however, the opposite results were found for CWD. The HRB CDD and CWD trends were overestimated and underestimated, respectively, followed by overestimated spatial variabilities. Overall, the PERSIANN-CDR had no $R$-based ability in producing spatial patterns of the trends of the duration-based indices, accompanied with no $K G E$-based ability.

(3) Validation for frequency-based indices. The PERSIANN-CDR could better capture spatial distributions of climatological R10mm, R20mm, and Rnnmm, with better $K G E$-based performance. For the HRB, magnitudes and spatial variabilities for the climatological values of each frequency-based index were differently underestimated and overestimated, respectively. Across the HRB, the R10mm underestimations and the R20mm and Rnnmm overestimations were widely distributed. For temporal variabilities, all the frequency-based indices were underestimated at most grids. In general, the PERSIANN-CDR had strong ability to represent temporal fluctuations of the three indices across the HRB. Moreover, there existed KGE-based ability for this product to detect these indices, especially for R10mm, with a better overall performance. For the HRB, the PERSIANN-CDR seriously underestimated the trends of the frequency-based indices and overestimated spatial variabilities of R10mm. No $R$-based ability and KGE-based ability existed for the PERSIANN-CDR to capture the trends of the frequency-based indices.

(4) Validation for intensity-based indices. The PERSIANN-CDR had ability to reproduce spatial patterns of climatological characteristics of the intensity-based indices, but with underestimated magnitudes. Except for SDII, the other two indices both corresponded to different underestimations in spatial variabilities of climatological values. This product had a moderate KGE-based performance in representing climatological values of the intensity-based indices. Across the HRB, the intensitybased indices were generally underestimated, but their temporal variabilities were overestimated. With the exception of R1xday, the PERSIANN-CDR exhibited ability to reproduce temporal variabilities of Rx5day and SDII across most of the HRB. No KGE-based ability was detected at most grids for Rx1day, while the PERSIANNCDR corresponded to a better and a certain KGE-based performance for Rx5day and SDII at most grids, respectively. As for the trends, underestimations existed in magnitudes and spatial variabilities for the intensity-based indices (except for Rx5day). The PERSIANN-CDR showed a certain $R$-based ability in reproducing spatial patterns of these indices' trends, but no KGE-based abilities existed.

A comprehensive assessment of the PERSIANN-CDR extreme precipitation over the HRB was conducted by comparing here with gauge measurements. However, it should be noted that there existed some issues-e.g., mismatch in spatial scale between point-scale gauge and areal satellite precipitation, inherent uncertainties for gauge observations (including calibration flaws, wind-related undercatch, wetting-evaporation losses, etc.), and inhomogeneity of observations-influencing the confidence level of our findings [39,47-52]. Because of precipitation with large variability at a small spatial extent, a sparse gauge network is difficult to use to fully detect precipitating processes at a given PERSIANN-CDR grid. Therefore, to minimize the related uncertainties into validation results, a sufficient number of gauges should be collected [47]. Commonly, gauges have flaws in calibration, consequently resulting in measured values with uncertainties. For instance, some studies have stated that calibration flaws tended to underestimate gauge observations, particu- 
larly for greater rainfall intensities [48]. Under wind-related undercatch effect, the catch efficiency of gauges becomes lower, more or less, mainly due to raindrops missing the funnel or falling at an inclination. As a result, the gauged-recorded precipitation is often smaller than the true values, and underestimations are closely associated with ambient wind speed, raindrop size distribution, and gauge design [49]. Moreover, the gauge values are likely to be underestimated because of evaporation from water adhering to the inside walls of the gauges (i.e., wetting losses) and exposure of the water surface within a gauge to atmosphere (i.e., evaporation losses) [50]. Simply, these influential factors of gauge measurements have an aggregate impact of underestimating gauge precipitation, which then propagate impact into our results [51]. In this study, although gauges with inhomogeneous observations were removed with the Pettitt test (a better method to examine observations' homogeneity when lacking meta-data for gauges; [40]), no guarantee shows that the records at the remaining gauges were all homogenous, potentially weakening the confidence level of this study.

Regardless, our study provides some significant reference data for PERSIANN-CDR developers and potential users in the HRB and other regions. For example, the different capacity of PERSIANN-CDR to detect various extreme precipitation indices suggests that PERSIANN-CDR developers might try to develop specific algorithms and/or correction procedures for increasing a certain validation metric-based performance; for potential users, some PERSIANN-CDR extreme precipitation indices (e.g., CWD, Rx1day, and Rx5day) with poor performance should be excluded from use. The poor performance of PERSIANNCDR for detecting linear trends of all the selected indices implies that more effort should be devoted by the developers to improving PERSIANN-CDR's abilities; moreover, more attention should be paid by potential users of PERSIANN-CDR when conducting studies of long-term changes in extreme precipitation.

Author Contributions: S.S., J.W., and W.S. conceived and designed this study. S.S., J.W., W.S., and R.C. were the main authors, whose work included data collection and analysis, interpretation of results, and manuscript preparation. G.W. played a supervisory role. S.S., J.W., W.S., and R.C. contributed by processing data and providing rain gauge observations. All authors discussed the results and revised the manuscript. All authors have read and agreed to the published version of the manuscript.

Funding: This work was jointly supported by the National Key Research and Development Program of China (Grant NOs. 2018YFC1507101 and 2017YFA0603701), the National Natural Science Foundation of China (Grant NOs. 42075189, 41605042, and 41875094), and the Qinglan Project of Jiangsu Province of China.

Acknowledgments: PERSIANN-CDR daily precipitation data were downloaded from the Centre for Hydrometeorology and Remote Sensing (CHRS) data portal with a website at http:/ / chrsdata. eng.uci.edu (accessed on 1 January 2021), while DEM data of SRTM3 are available from http:/ / srtm. csi.cgiar.org/index.asp (accessed on 1 January 2021). Notably, daily precipitation observations at more than 200 gauge sites are not available to the public, but they can be obtained and used through cooperation with the CMA. We thank all data developers and their managers and funding agencies, whose work and support were essential for obtaining the datasets, without which the analyses conducted in this study would have been impossible. In addition, source code for conducting this study is available from the authors upon request (sun.s@nuist.edu.cn).

Conflicts of Interest: The authors declare no conflict of interest.

\section{References}

1. IPCC. Summary for policymakers. Climate Change 2014: Impacts, Adaptation, and Vulnerability. Part A: Global and Sectoral Aspects. Contribution of Working Group ii to the Fifth Assessment Report of the Intergovernmental Panel on Climate Change; Field, C.B., Barros, V.R., Dokken, D.J., Mach, K.J., Mastrandrea, M.D., Bilir, T.E., Chatterjee, M., Ebi, K.L., Estrada, Y.O., Genova, R.C., et al., Eds.; Cambridge University Press: Cambridge, UK, 2014; pp. 1-32.

2. Milly, P.; Wetherald, R.; Dunne, K.A.; Delworth, T.L. Increasing risk of great floods in a changing climate. Nature 2002, 415, 514-517. [CrossRef] 
3. Wang, G.L. Lessons learned from protective measures associated with the 2010 Zhouqu debris flow disaster in China. Nat. Hazards 2013, 69, 1835-1847. [CrossRef]

4. Witze, A. Why extreme rains are gaining strength as the climate warms. Nature 2018, 563, 458-460. [CrossRef]

5. Amarnath, G.; Yoshimoto, S.; Goto, O.; Fujihara, M.; Smakhtin, V.; Aggarwal, P.K.; Ravan, S. Global Trends in Water-Related Disasters Using Publicly Available Database for Hazard and Risk Assessment. Available online: https://cgspace.cgiar.org/ bitstream/handle/10568/93032/H048407.pdf (accessed on 3 August 2020).

6. Lynch, S.L.; Schumacher, R.S. Ensemble-based analysis of the May 2010 extreme rainfall in Tennessee and Kentucky. Mon. Weather Rev. 2014, 142, 222-239. [CrossRef]

7. Martius, O.; Sodemann, H.; Joos, H.; Pfahl, S.; Winschall, A.; Croci-Maspoli, M.; Sprenger, M.; Wernli, H.; Sedláček, J.; Schemm, S.; et al. The role of upper-level dynamics and surface processes for the Pakistan flood of July 2010. Q. J. Roy. Meteorol. Soc. 2013, 139, 1780-1797. [CrossRef]

8. Ávila, Á.; Guerrero, F.C.; Escobar, Y.C.; Justino, F. Recent Precipitation Trends and Floods in the Colombian Andes. Water 2019, 11, 379. [CrossRef]

9. Duan, W.; He, B.; Nover, D.; Fan, J.; Yang, G.; Chen, W.; Meng, H.; Liu, C. Floods and associated socioeconomic damages in China over the last century. Nat. Hazards 2016, 82, 401-413. [CrossRef]

10. Tustison, B.; Harris, D.; Foufoula-Georgiou, E. Scale issues in verification of precipitation forecasts. J. Geophysi. Res. Atmos. 2001, 106, 11775-11784. [CrossRef]

11. Alijanian, M.; Rakhshandehroo, G.R.; Mishra, A.K.; Dehghani, M. Evaluation of satellite rainfall climatology using CMORPH, PERSIANN-CDR, PERSIANN, TRMM, MSWEP over Iran. Int. J. Climatol. 2017, 37, 4896-4914. [CrossRef]

12. Westrick, K.J.; Mass, C.F.; Colle, B.A. The limitations of the WSR-88D radar network for quantitative precipitation measurement over the Coastal Western United States. Bull. Am. Meteorol. Soc. 1999, 80, 2289-2298. [CrossRef]

13. Young, C.B.; Nelson, B.R.; Bradley, A.A.; Smith, J.A.; Peters-Lidard, C.D.; Kruger, A.; Baeck, M.L. An evaluation of NEXRAD precipitation estimates in complex terrain. J. Geophysi. Res. Atmos. 1999, 104, 19691-19703. [CrossRef]

14. AghaKouchak, A.; Behrangi, A.; Sorooshian, S.; Hsu, K.; Amitai, E. Evaluation of satellite-retrieved extreme precipitation rates across the central United States. J. Geophysi. Res. Atmos. 2011, 116. [CrossRef]

15. Huffman, G.J. README for Accessing Experimental Realtime TRMM Multi-Satellite Precipitation Analysis (Tmpart) Data Sets. NASA Tech. Doc. 2015; p. 12. Available online: Ftp://mesoa.gsfc.nasa.gov/pub/trmmdocs/rt/3B4XRT_README.pdf (accessed on 1 January 2020).

16. Joyce, R.J.; Janowiak, J.E.; Arkin, P.A.; Xie, P. CMORPH: A method that produces global precipitation estimates from passive microwave and infrared data at high spatial and temporal resolution. J. Hydrometeorol. 2014, 5, 487-503. [CrossRef]

17. Maggioni, V.; Sapiano, M.R.P.; Adler, R.F. Estimating uncertainties in high-resolution satellite precipitation products: Systematic or random error? J. Hydrometeorol. 2016, 17, 1119-1129. [CrossRef]

18. Sorooshian, S.; AghaKouchak, A.; Arkin, P.; Eylander, J.; Foufoula-Georgiou, E.; Harmon, R.; Hendrickx, J.M.H.; Imam, B.; Kuligowski, R.; Skahill, B.; et al. Advanced concepts on remote sensing of precipitation at multiple scales. Bull. Am. Meteorol. Soc. 2011, 92, 1353-1357. [CrossRef]

19. Huffman, G.J.; Adler, R.F.; Bolvin, D.T.; Gu, G.; Nelkin, E.J.; Bowman, K.P.; Yong, Y.; Stocker, E.F.; Wolff, D.B. The TRMM Multisatellite Precipitation Analysis (TMPA): Quasi-global, multi-year, combined-sensor precipitation at fine scales. J. Hydrometeorol. 2007, 8, 38-55. [CrossRef]

20. Funk, C.C.; Peterson, P.J.; Landsfeld, M.F.; Pedreros, D.H.; Verdin, J.P.; Sukla, S.; Husak, G.J.; Rowland, J.D.; Harrison, L.; Hoell, A.; et al. The climate hazards infrared precipitation with stations-A new environmental record for monitoring extremes. Sci. Data 2015, 2, 150066. [CrossRef]

21. Shen, Y.; Xiong, A.; Wang, Y.; Xie, P. Performance of high-resolution satellite precipitation products over China. J. Geophysi. Res. Atmos. 2010, 115. [CrossRef]

22. Tan, M.; Ibrahim, A.; Duan, Z.; Cracknell, A.; Chaplot, V. Evaluation of six high-resolution satellite and ground-based precipitation products over Malaysia. Remote Sens. 2015, 7, 1504-1528. [CrossRef]

23. Liu, X.; Yang, T.; Hsu, K.; Liu, C.; Sorooshian, S. Evaluating the streamflow simulation capability of PERSIANN-CDR daily rainfall products in two river basins on the Tibetan Plateau. Hydrol. Earth Syst. Sci. 2017, 21, 169-181. [CrossRef]

24. She, D.; Xia, J.; Zhang, Y.; Du, H. The trend analysis and statistical distribution of extreme rainfall events in the Huaihe River Basin in the past 50 years. Acta Geo. Sin. 2011, 66, 1200-1210. (In Chinese with English Abstract)

25. Bi, B.; Jiao, M.; Li, Z. Contrast analysis of meteorological and hydrological features of extremely heavy rainfall causing severe floods in Huai River Valley. J. Nanjing Inst. Meteorol. 2004, 27, 577-586. (In Chinese with English Abstract)

26. Wei, F.; Zhang, T. Oscillation characteristics of summer precipitation in the Huaihe River valley and relevant climate background. Sci. China Earth Sci. 2009, 39, 1360-1374. (In Chinese) [CrossRef]

27. Zhang, J. The 2003 floods in Huai River Basin. Meteorol. Knowl. 2003, 5, 2-4. (In Chinese)

28. Yin, J.; Yan, D.; Yang, Z.; Yuan, Z.; Yuan, Y.; Zhang, C. Projection of extreme precipitation in the context of climate change in Huang-Huai-Hai region, China. J. Earth Syst. Sci. 2016, 125, 417-429. [CrossRef]

29. Miao, C.; Ashouri, H.; Hsu, K.-L.; Sorooshian, S.; Duan, Q. Evaluation of the PERSIANN-CDR daily rainfall estimates in capturing the behavior of extreme precipitation events over China. J. Hydrometeorol. 2015, 16, 1387-1396. [CrossRef] 
30. Liu, J.; Xu, Z.; Bai, J.; Peng, D.; Ren, M. Assessment and correction of the PERSIANN-CDR product in the Yarlung Zangbo River Basin, China. Remote Sens. 2018, 10, 2031. [CrossRef]

31. Liu, J.; Xia, J.; She, D.; Li, L.; Wang, Q.; Zou, L. Evaluation of six satellite-based precipitation products and their ability for capturing characteristics of extreme precipitation events over a climate transition area in China. Remote Sens. 2019, $11,1477$. [CrossRef]

32. Gao, F.; Zhang, Y.; Chen, Q.; Wang, P.; Yang, P.; Yao, Y.; Cai, W. Comparison of two long-term and high-resolution satellite precipitation datasets in Xinjiang, China. Atmos. Res. 2018, 212, 150-157. [CrossRef]

33. Gupta, H.V.; Kling, H.; Yilmaz, K.K.; Martinez, G.F. Decomposition of the mean squared error and NSE performance criteria: Implications for improving hydrological modelling. J. Hydrol. 2012, 377, 80-91. [CrossRef]

34. Sun, S.; Shi, W.; Zhou, S.; Chai, R.; Chen, H.; Wang, G.; Zhou, Y.; Shen, H. Capacity of satellite-based and reanalysis precipitation products in detecting long-term trends across Mainland China. Remote Sens. 2020, 12, 2902. [CrossRef]

35. Chen, F.; Gao, Y. Evaluation of precipitation trends from high-resolution satellite precipitation products over Mainland China. Clim. Dyn. 2018, 51, 3311-3331. [CrossRef]

36. Ashouri, H.; Hsu, K.; Sorooshian, S.; Braithwaite, D.K.; Knapp, K.R.; Cecil, L.D.; Nelson, B.R.; Prat, O.P. PERSIANNCDR: Daily precipitation climate data record from multi-satellite observations for hydrological and climate studies. Bull. Am. Meteorol. Soc. 2015, 96, 69-83. [CrossRef]

37. Estévez, J.; Gavilán, P.; Giráldez, J.V. Guidelines on validation procedures for meteorological data from automatic weather stations. J. Hydrol. 2011, 402, 144-154. [CrossRef]

38. Gentilucci, M.; Barbieri, M.; Burt, P.; D'Aprile, F. Preliminary data validation and reconstruction of temperature and precipitation in Central Italy. Geosciences 2018, 8, 202. [CrossRef]

39. Zahumenský, I. Guidelines on Quality Control Procedures for Data from Automatic Weather Stations; World Meteorological Organization: Geneva, Switzerland, 2004.

40. Wijngaard, J.B.; Tank, A.M.G.K.; Konnen, G.P. Homogeneity of 20th century European daily temperature and precipitation series. Int. J. Climatol. 2003, 23, 679-692. [CrossRef]

41. Katiraie-Boroujerdy, P.S.; Nasrollahi, N.; Hsu, K.-L.; Sorooshian, S. Evaluation of satellite-based precipitation estimation over Iran J. Arid. Environ. 2013, 97, 205-219. [CrossRef]

42. Alexander, L.V.; Zhang, X.; Peterson, T.C.; Caesar, J.; Klein, T.A.M.G.; Haylock, M.; Collins, D.; Trewin, B.; Rahimzadeh, F.; Tgipour, A.; et al. Global observed changes in daily climate extremes of temperature and precipitation. J. Geophys. Res. Atmos. 2006, 111. [CrossRef]

43. Kim, Y.H.; Min, S.K.; Zhang, X.B.; Zwiers, F.; Alexander, L.V.; Donat, M.G.; Tung, Y.-S. Attribution of extreme temperature changes during 1951-2010. Clim. Dyn. 2016, 46, 1769-1782. [CrossRef]

44. Donat, M.G.; Alexander, L.V.; Yang, H.; Durre, I.; Vose, R.; Caesar, J. Global land-based datasets for monitoring climatic extremes. Bull. Am. Meteorol. Soc. 2013, 94, 997-1006. [CrossRef]

45. Yin, H.; Sun, Y. Detection of anthropogenic influence on fixed threshold indices of extreme temperature. J. Clim. 2018, 31, 6341-6352. [CrossRef]

46. Cerón, W.L.; Kayano, M.T.; Andreoli, R.V.; Avila-Diaz, R.; Ayes, I.; Freitas, E.D.; Martins, J.A.; Souza, R.A.F. Recent intensification of extreme precipitation events in the La Plata Basin in Southern South America (1981-2018). Atmos. Res. 2020, $249,105299$. [CrossRef]

47. Villarini, G.; Mandapaka, P.V.; Krajewski, W.F.; Moore, R.J. Rainfall and sampling uncertainties: A rain gauge perspective. J. Geophysi. Res. Atmos. 2008, 113. [CrossRef]

48. Shedekar, V.S.; King, K.W.; Fausey, N.R.; Soboyejo, A.B.O.; Harmel, R.D.; Brown, L.C. Assessment of measurement errors and dynamic calibration methods for three different tipping bucket rain gauges. Atmos. Res. 2016, 178, 445-458. [CrossRef]

49. Pollock, M.D.; O’Donnell, G.; Quinn, P.; Dutton, M.; Black, A.; Wilkinson, M.E.; Colli, M.; Stagnaro, M.; Lanza, L.G.; Lewis, E.; et al. Quantifying and mitigating wind-Induced undercatch in rainfall measurements. Water Resour. Res. 2018, 54, $3863-3875$. [CrossRef]

50. Adam, J.C.; Lettenmaier, D.P. Adjustment of global gridded precipitation for systematic bias. J. Geophysi. Res. Atmos. 2003, 108. [CrossRef]

51. Morbidelli, R.; Saltalippi, C.; Flammini, A.; Corradini, C.; Wilkinson, S.M.; Fowler, H.J. Influence of temporal data aggregation on trend estimation for intense rainfall. Adv. Water. Res. 2018, 122, 304-316. [CrossRef]

52. Yang, D.; Ohata, T. A bias-corrected Siberian regional precipitation climatology. J. Hydrometeorol. 2001, 2, 122-139. [CrossRef] 